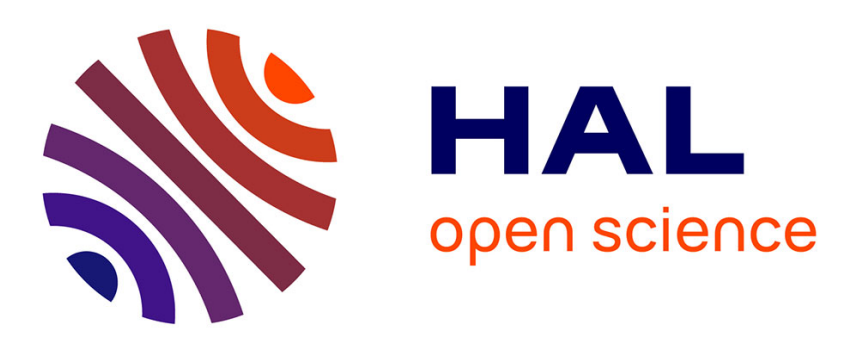

\title{
Transient performance evaluation of waste heat recovery rankine cycle based system for heavyduty trucks
}

\author{
Vincent Grelet, Thomas Reiche, Vincent Lemort, Madiha Nadri, Pascal
}

Dufour

\section{- To cite this version:}

Vincent Grelet, Thomas Reiche, Vincent Lemort, Madiha Nadri, Pascal Dufour. Transient performance evaluation of waste heat recovery rankine cycle based system for heavyduty trucks. Applied Energy, 2016, 165 (1), pp.878-892. 10.1016/j.apenergy.2015.11.004 . hal-01265044

\section{HAL Id: hal-01265044 \\ https://hal.science/hal-01265044}

Submitted on 30 Jan 2016

HAL is a multi-disciplinary open access archive for the deposit and dissemination of scientific research documents, whether they are published or not. The documents may come from teaching and research institutions in France or abroad, or from public or private research centers.
L'archive ouverte pluridisciplinaire HAL, est destinée au dépôt et à la diffusion de documents scientifiques de niveau recherche, publiés ou non, émanant des établissements d'enseignement et de recherche français ou étrangers, des laboratoires publics ou privés.

\section{(c)(1)}

Distributed under a Creative Commons Attribution| 4.0 International License 
This document must be cited according to its final version which is published in a journal as:

V. Grelet, T. Reiche, V. Lemort, M. Nadri, P. Dufour, "Transient performance evaluation of waste heat recovery rankine cycle based system for heavyduty trucks", Applied Energy, 2016, 165(1), pp. 878-892.

DOI : 10.1016/j.apenergy.2015.11.004

You downloaded this document from the CNRS open archives server, on the webpages of Pascal Dufour: http://hal.archives-ouvertes.fr/DUFOUR-PASCAL-C-3926-2008 


\title{
TRANSIENT PERFORMANCE EVALUATION OF WASTE HEAT RECOVERY RANKINE CYCLE BASED SYSTEM FOR HEAVY DUTY TRUCKS
}

\author{
Vincent Grelet ${ }^{\mathrm{a}, \mathrm{b}, \mathrm{c}}$, Thomas Reiche ${ }^{\mathrm{a}}$, Vincent Lemort ${ }^{\mathrm{b}, *}$, Madiha Nadri ${ }^{\mathrm{c}}$, \\ Pascal Dufour ${ }^{\mathrm{c}}$ \\ ${ }^{a}$ Volvo Trucks Global Trucks Technology Advanced Technology and Research, 1 av Henri \\ Germain 69800 Saint Priest, France, (vincent.grelet@volvo.com, \\ thomas.reiche@volvo.com). \\ ${ }^{b}$ LABOTHAP, University of Liege, Campus du Sart Tilman Bat. $B 49$ B4000 Liege, \\ Belgium,(vincent.lemort@ulg.ac.be). \\ ${ }^{c}$ Universite de Lyon, F-69622, Lyon, France, Universite Lyon 1, Villeurbanne, France, \\ CNRS, UMR 5007, LAGEP, (nadri@lagep.univ-lyon1.fr, dufour@lagep.univ-lyon1.fr).
}

\begin{abstract}
The study presented in this paper aims to evaluate the transient performance of a waste heat recovery Rankine cycle based system for a heavy duty truck and compare it to steady state evaluation. Assuming some conditions to hold, simple thermodynamic simulations are carried out for the comparison of several fluids. Then a detailed first principle based model is also presented. Last part is focused on the Rankine cycle arrangement choice by means of model based evaluation of fuel economy for each concept where the fuels savings are computed using two methodologies. Fluid choice and concept optimization are conducted taking into account integration constraints (heat rejection, packaging ...). This paper shows the importance of the modeling phase when designing Rankine cycle based heat recovery systems and yields a better understanding when it comes to a vehicle integration of a Rankine cycle in a truck.
\end{abstract}

Keywords: Waste heat recovery system, Modeling, Thermodynamic,

\footnotetext{
${ }^{*}$ Corresponding author
} 
Rankine cycle, Heavy duty trucks

\section{INTRODUCTION}

2 Even in nowadays heavy duty (HD) engines, which can reach $45 \%$ of effi3 ciency, a high amount of the chemical energy contained in the fuel is released as heat to the ambient. Driven by future emissions legislation and increase in fuel prices, engine gas heat recovering has recently attracted a lot of interest. Over the last decades, most of the research has focused on waste heat recovery systems (WHRS) based on the Rankine cycle [1, 2, 3]. These systems can lead to a decrease in fuel consumption and lower engine emissions [4, 5]. Recent studies have brought a significant potential for such systems in a HD vehicle [6, 7]. However, before the Rankine cycle based system can be applied to commercial vehicles, the challenges of its integration have to be faced. The work done in [8] and [9] show that one of the main limitation is the cooling capacity of the vehicle. But other drawbacks, such as the back pressure, weight penalty or transient operation should not be minimized 10, 11]. Before tackling the problem of the control strategy of this system [12, 4], the architecture and components need to be selected to achieve a certain objective that could be to maximize the fuel savings or minimize the impact on the vehicle. This study focuses more on maximizing the system performance by taking into account the different penalties induced by the integration of the system on a heavy duty truck. Technical challenges and optimization of stationary organic Rankine cycles (ORC) are well adressed [13, 14] but for mobile applications only few studies deal with fuel saving potential of WHRS on dynamic driving cycles [15, 16] and the latter is generally reduced to a certain number of steady state engine operating points [17, 18]. This last approach leads to an overestimation of the WHRS performance [3] and therefore of the fuel economy. In [19] different concepts are analyzed taking into account the system integration into the vehicle cooling module. The concepts differ in the number of heat sources used and the temperature level of the cooling fluid. Each is simulated on different steady state engine operating points and the fuel economy is calculated taking into account the increase in cooling fan consumption, exhaust back pressure or intake manifold temperature. Depending on the Rankine configuration and the location of the condenser, improvements from $2.2 \%$ (recovering heat only from exhaust 
gases and condenser placed in front of the cooling package) to $6.9 \%$ (exhaust gas recirculation and exhaust heat are recovered and condenser is fed with engine coolant) are achieved. In [15], dynamic fuel economy is evaluated on a light duty vehicle taking into account the main penalties induced by the integration of the WHRS. Fuel savings from 3.4\% to 1.3\% are presented depending on the level of integration of the system into the vehicle architecture. However, no optimization is proposed either on the system architecture or on the condenser integration into the cooling package. This paper is organized as follows. The second section explains the different considerations to take when designing a Rankine cycle for a HD application. In the third section, the different models used in the rest of the study are explained. In the fourth section, the scope of the study and the different methodologies are explained. In the fifth section, simulation results are analyzed and possible improvements are proposed. Finally, conclusions are drawn and directions for future research work are discussed.

\section{DESIGN ASPECTS TO CONSIDER}

Figure 1 shows a simple waste heat recovery system mounted on a 6 cylinder heavy duty engine. Working fluid flows through four basic components which are: the pump, the evaporator linked to the heat source, the expansion machine and the condenser linked to the heat sink. For sake of clarity, the link between the expander and the engine driveline is represented by a dashed line since it can be either mechanical or electrical (by coupling a generator to the expansion machine and reinject the electricity on the on board network).

\subsection{Working fluid choice}

There are several aspects to take into account when choosing a working fluid for this application. Unlike stationary power plants where the main consideration is the output power or the efficiency, here other aspects have to be considered such as fluid deterioration, environmental aspects or freezing. Up to now, several studies have tried to identify the ideal fluid for WHRS [20, 21, 22] but no single fluid has been found. Recently, new performance indicators have been introduced [14, 23], where cost and design issues enter into consideration. 


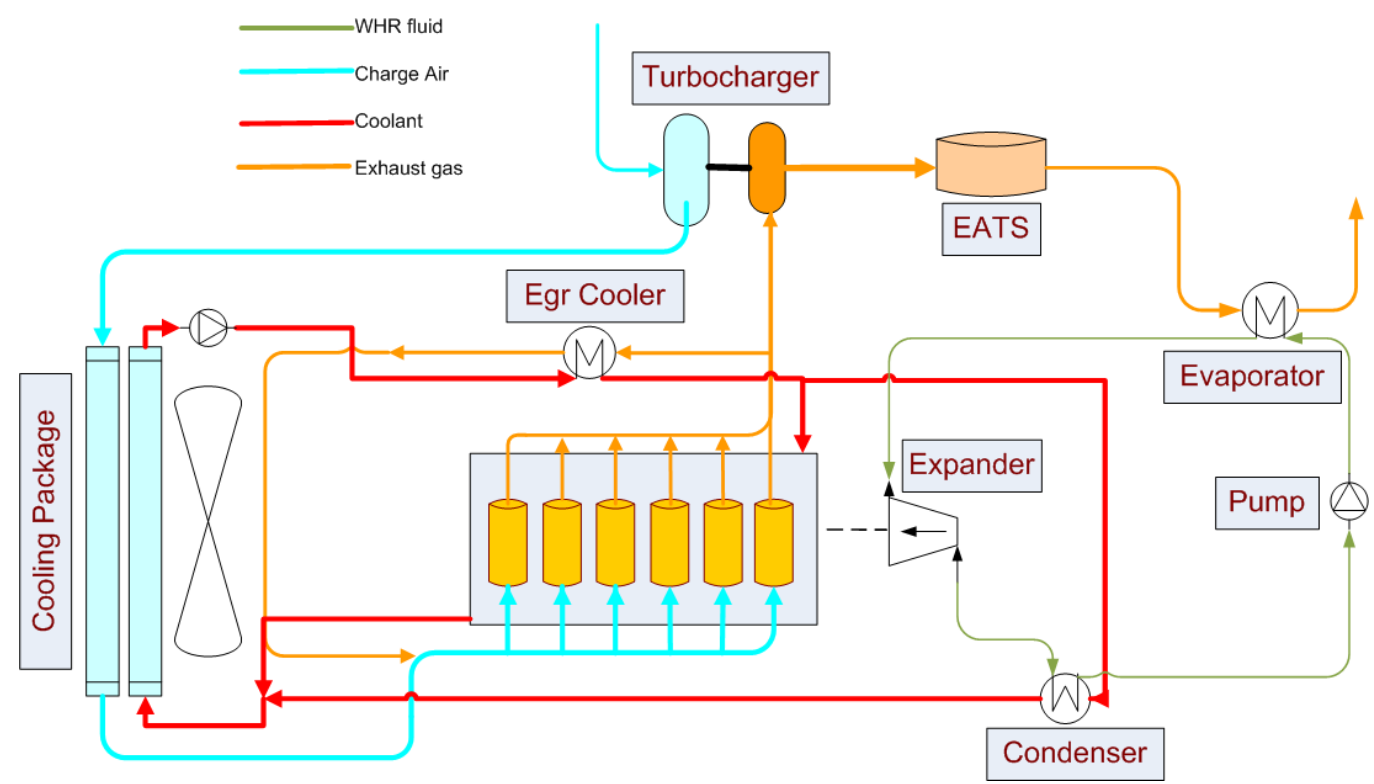

Figure 1: Simple waste heat recovery Rankine based system

\subsection{Heat sources}

On a commercial vehicle, a certain number of heat sources can be found such as exhaust gases, cooling water or engine oil. These ones have several grade of quality (temperature level) and quantity (amount of energy). If the number of heat sources often yields higher fuel savings, it also brings more complexity and more challenges for the design of the system (fluid, expansion machine, control).

\subsection{Heat $\operatorname{sink}$}

On a HD Truck, the only heat sink available is the vehicle cooling package which is a module including radiators for the compressed air and the engine coolant and cooled down by means of the ram air effect and the cooling fan. Integration of a WHRS into the cooling module results on a higher load on the latter and limits the amount of waste heat that can be converted into useful work. As such, complete system analysis is necessary to find the optimal way of recovering heat from a vehicle. 


\subsection{Subsystem interaction}

The engine operation is influenced by the introduction of a WHRS. For example, as the WHRS shares the cooling system of the vehicle, the charge air cooling capacity can be lower, which has a negative behavior on the engine performance. Another example is the use of exhaust gas recirculation (EGR) as heat source. This leads to a trade-off between EGR cooling and Rankine cycle performance, which could impact negatively the engine emissions. Several other interactions such as the exhaust back pressure or the weight penalty could be cited.

The WHRS performance, and so the fuel economy induced by this later, is then dependent on all these aspects. It is therefore critical to model the complete system and its environment in order to optimize its architecture. It helps to select the best design and reduce the number of experimental tests to carry out.

\section{RANKINE MODELING}

\subsection{Rankine process}

The Temperature Entropy (T-s) diagram represented in figure 2 shows the associated state changes of the working fluid through the Rankine cycle:

- The pressure of the liquid is increased by the pump work up to the evaporating pressure $(1 \rightarrow 2)$.

- The pressurized working fluid is pre-heated $(2 \rightarrow 3 \mathrm{a})$, vaporized $(3 \mathrm{a} \rightarrow$ $3 \mathrm{~b})$ and superheated $(3 \mathrm{~b} \rightarrow 3 \mathrm{c})$ in a heat exchanger, by recovering heat $\left(\dot{Q}_{i n}\right)$ from the heat source.

- The superheated vapor expands from evaporating pressure to condensing pressure $(3 \mathrm{c} \rightarrow 4)$ in an expansion device creating mechanical power $\left(\dot{W}_{\text {out }}\right)$.

- The expanded vapor condenses $(4 \rightarrow 1)$ through a condenser (linked to the heat sink) releasing heat $\left(\dot{Q}_{\text {out }}\right)$.

In this process the changes of states in both the pump and the expander are irreversible and increase the fluid entropy to a certain extent. To correctly assess the performance of a system based on the Rankine cycle, two different 


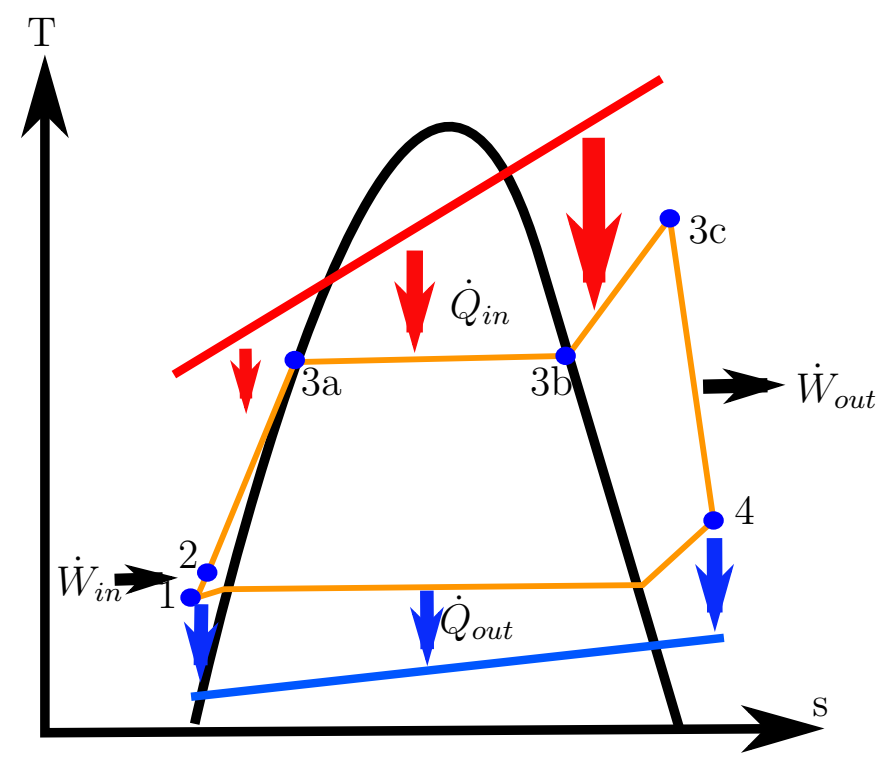

Figure 2: Temperature-Entropy diagram of the Rankine cycle

models have been developed: a simple 0D steady state model based on the enthalpy change that undergoes the working fluid which does not intend to represent components performance and where the dynamic is not taken into account and a second, based on conservation principles applied on one spatial dimension. This is required to represent real performance of the components constituting the system either in steady state or in transient.

\subsection{OD steady state modeling of a Rankine cycle}

In order to simulate a high number of working fluids, a 0D model of a Rankine cycle using one heat source is developed. It does not represent a real system but it allows a fast assessment of a various number of working fluids. It helps to select the suitable working fluids for the studied application. This model is based on the enthalpy changes in the process described in section 3.1 . This model is able to perform either subcritical or supercritical cycle, which avoids the vaporization process and leads to a smaller system and a better heat recovery process [24]. Those relations are verified as long as the heat losses in the system and in the components are neglected. The 0D model 
used is given by the system of equations (1):

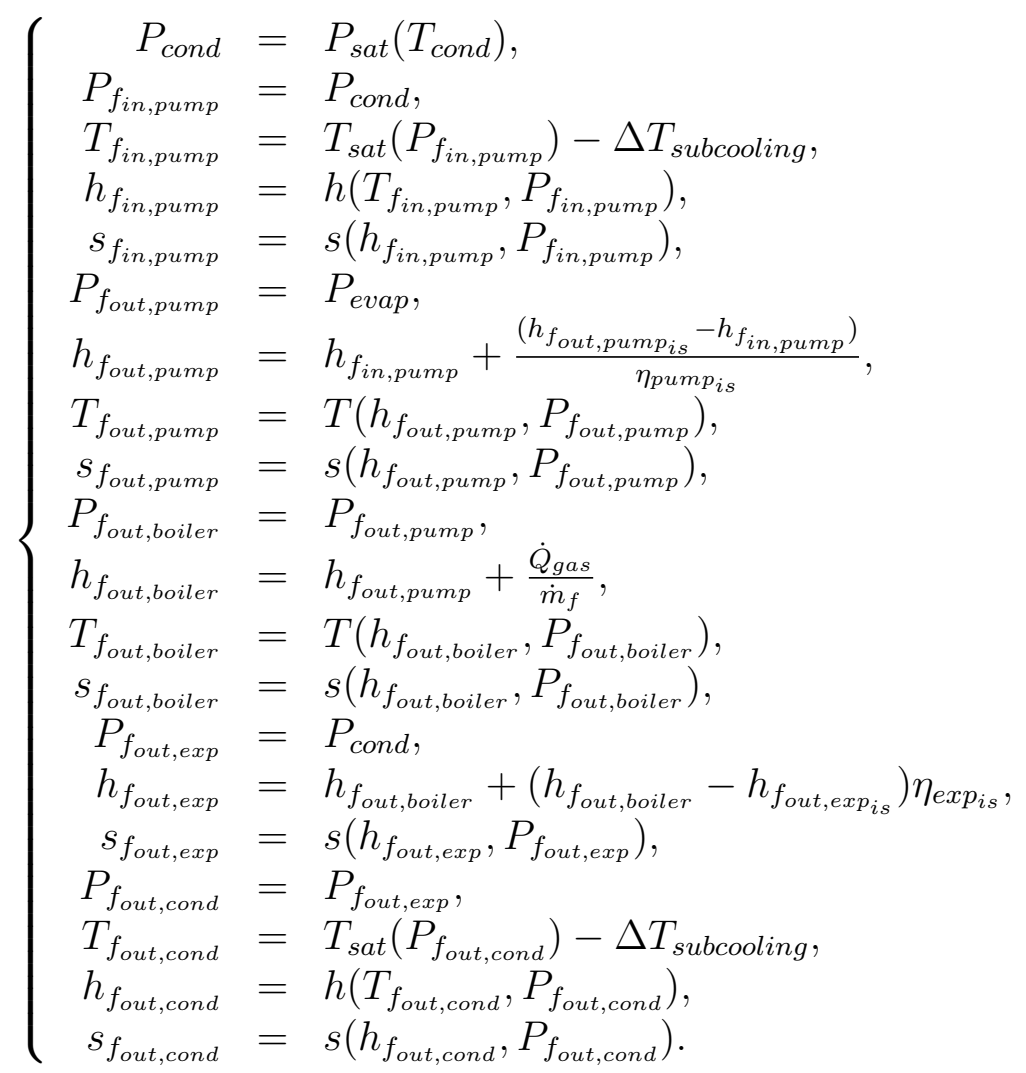

where

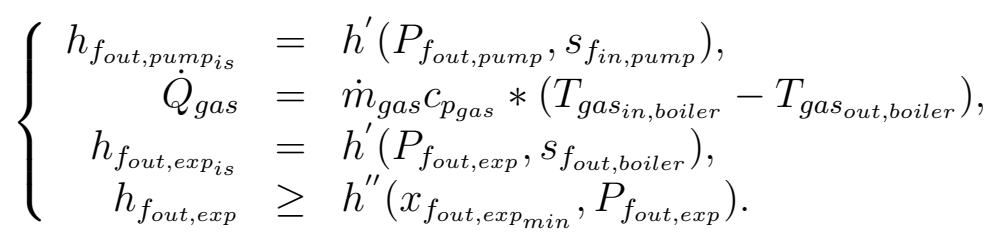

In table 1 one can find the simulation model parameters, and the abbreviations are given in the appendix. In addition to that, a routine verifying that the pinch point $(P P)$ is respected during the evaporation process. Refprop database [25] is used to compute the following quantity: $h, s, T, P_{\text {sat }}$ and $T_{\text {sat }}$. Input variables of the model (1) are the gas mass flow and temperature (denoted by $\dot{m}_{\text {gas }}$ and $T_{\text {gas }}$ in,boiler $)$ entering in the system and the condensing temperature $\left(T_{\text {cond }}\right)$. Outputs of the model are the power produced by the 


\begin{tabular}{|c|c|c|c|}
\hline Model parameters & Variable in (1) & unit & value \\
\hline Pump isentropic efficiency & $\eta_{\text {pump }}$ & $\%$ & 65 \\
\hline Expander isentropic efficiency & $\eta_{\exp _{i s}}$ & $\%$ & 70 \\
\hline Maximum evaporating pressure & $P_{\text {evap }}$ & bar & 40 \\
\hline Minimum condensing pressure & $P_{\text {cond }}$ & bar & 1 \\
\hline Maximum pressure ratio & $\frac{P_{\text {evap }}}{P_{\text {con }}}$ & - & $40: 1$ \\
\hline Pinch points HEX & $P P$ & $\mathrm{~K}$ & 10 \\
\hline Pressure ratio among HEX & $\frac{P_{f_{\text {out }, \text { boiler }}}}{P_{f_{\text {out }} \text { pump }}}$ & - & 1 \\
\hline Minimum quality after expansion & $x_{f_{\text {out }, \exp , \min }}$ & - & 0.9 \\
\hline
\end{tabular}

Table 1: 0D model parameters

expansion $\dot{W}_{\text {exp }}$, the power consummed by the compression $\dot{W}_{\text {pump }}$ and the net output power NOP which are defined as:

$$
\left\{\begin{aligned}
\text { NOP } & =\dot{W}_{\text {exp }}-\dot{W}_{\text {pump }}, \\
\dot{W}_{\text {exp }} & =\dot{m}_{f} *\left(h_{f_{\text {in }, \text { exp }}}-h_{f_{\text {out }, \text { exp }}}\right), \\
\dot{W}_{\text {pump }} & =\dot{m}_{f} *\left(h_{f_{\text {in }, \text { pump }}}-h_{f_{\text {out }, \text { pump }}}\right) .
\end{aligned}\right.
$$

The model 1 is not dynamic and does not represent any real components performance. A dynamic 1D model is therefore developed to evaluate the system performance on more realistic dynamic driving conditions.

\subsection{D dynamic modeling of a Rankine cycle}

\subsubsection{Tank}

The reservoir is modeled by a fixed volume, which can be either vented to the atmosphere or be hermetic (depending on the condensing pressure) in order to avoid sub atmospheric conditions. Mass and energy conservation equations are:

$$
\left\{\begin{aligned}
\dot{m}_{f_{\text {out tank }}}-\dot{m}_{f_{\text {in,tank }}} & =\frac{\partial m_{f_{\text {tank }}}}{\partial t} \\
\dot{m}_{f_{\text {in }, \text { tank }}} h_{f_{\text {in,tank }}}-\dot{m}_{f_{\text {out }, \text { tank }}} h_{f_{\text {out }, \text { tank }}} & =m_{f_{\text {tank }}} \frac{\partial h_{f_{\text {tank }}}}{\partial t} .
\end{aligned}\right.
$$




\subsubsection{Working fluid pump}

The working fluid pump is simply represented by a fixed displacement and isentropic efficiency. The volumetric efficiency is a function of the outlet pressure. This law is identified thanks to experimental data:

$$
\dot{m}_{f_{\text {out }, \text { pump }}}=\rho_{f_{\text {in }, \text { pump }}} \frac{N_{\text {pump }}}{60} C_{c_{\text {pump }}} \eta_{\text {pump pol }} .
$$

The outlet enthalpy is calculated as shown in the equation for $h_{f_{\text {out }, \text { pump }}}$ in the 0D model (1).

\subsubsection{Heat exchangers: Evaporator(s) and condenser(s)}

The models are developed to dynamically predict temperature and enthalpy of transfer and working fluid at the outlet of each heat exchanger (HEX). When coming to dynamic models of those components, two methodologies can be found in the literature: moving boundary (MB) and finite volume (FV) models. Usually more complex in terms of computational capacity needed due to the high number of system states, the FV approach has the advantage to be more powerful and robust concerning the prediction. Both approaches have been widely used in large power recovery system and control system design [26, 27, 28, 29] and results in a simplification of the heat recovery boiler/condenser geometry in a great extent (i.e. by representing the boiler by a straight pipe in pipe counterflow heat exchanger). In this study, the FV approach is preferred since it easily handles starting and shut down phases [30] when only few papers adressed those cases with a MB approach 31.

\section{Model assumptions}

Several assumptions are done to simplify the problem in a great extent. These ones are usually admitted when coming to heat exchanger modeling [32, 26]:

- The transfer fluid is always considered in single phase, i.e. no condensation in the EGR/exhaust gases is taken into account.

- The conductive heat fluxes are neglected since the predominant phenomenon is the convection.

- All HEX are represented by a straight pipe in pipe counterflow heat exchanger of length $L$. 
- Fluid properties are considered homogeneous in a volume.

- Pressure dynamics is neglected since it is very fast compared to those of heat exchanger.

\section{Governing equations}

Boiler(s) and condenser(s) models are based on mass and energy conservation principles.

- Working fluid (internal pipe):

$$
\left\{\begin{array}{l}
A_{\text {cross }_{f}} \frac{\partial \rho_{f}}{\partial t}+\frac{\partial \dot{m}_{f}}{\partial z}=0 \\
A_{\text {cross }_{f}} \frac{\partial \rho_{f} h_{f}}{\partial t}+\frac{\partial \dot{m}_{f} h_{f}}{\partial z}+\dot{q}_{\text {conv }_{f_{i n t}}}=0 \\
\dot{q}_{\text {conv }_{f_{i n t}}}=\alpha_{f} P e_{\text {exch }_{f}}\left(T_{f}-T_{\text {wall }_{i n t}}\right) .
\end{array}\right.
$$

- Internal pipe wall: An energy balance is expressed at the wall between the working fluid and the gas and is expressed as follows:

$$
\dot{Q}_{\text {conv }_{f_{i n t}}}+\dot{Q}_{\text {conv }_{g_{i n t}}}=\rho_{\text {wall }} c_{p_{\text {wall }}} V_{\text {wall }_{\text {int }}} \frac{\partial T_{\text {wall }} \text { int }}{\partial t} .
$$

- Gas side (external pipe): The energy conservation is then formulated under the following form:

$$
\rho_{g} A_{\text {cross }_{g}} c_{p_{g}} \frac{\partial T_{g}}{\partial t}+c_{p_{g}} \dot{m}_{g} \frac{\partial T_{g}}{\partial z}+\dot{q}_{\text {conv }_{g_{i n t}}}+\dot{q}_{\text {conv }_{g_{e x t}}}=0,
$$

where the convection on the external side is used to represent the heat losses to the ambient.

- External pipe wall: As for the internal pipe an energy balance is expressed between the gas and the ambient:

$$
\dot{Q}_{\text {conv }_{g_{e x t}}}+\dot{Q}_{\text {conv }_{a m b e x t}}=\rho_{w_{a l l}} c_{p_{w a l l}} V_{w_{a l l} x t} \frac{\partial T_{w_{a l l}}{ }_{e x t}}{\partial t}
$$

194 In equation (7) and $(9)$ the convection heat flow rate $\left(\dot{Q}_{\text {conv }}\right)$ is expressed as:

$$
\begin{aligned}
\dot{Q}_{\text {conv }_{j_{k}}} & =\alpha_{j} A_{\text {exch }_{j_{k}}}\left(T_{\text {wall }_{k}}-T_{j}\right), \\
\text { where } j & =g, f, \text { amb } \\
\text { and } k & =\text { int, ext. }
\end{aligned}
$$


Furthermore, to complete the system, one need boundary and initial conditions. Time-dependent boundary conditions are used at $z=0$ and $z=L$ $(t>0)$ :

$$
\begin{aligned}
\dot{m}_{f}(t, 0) & =\dot{m}_{f_{0}}(t), \\
h_{f}(t, 0) & =h_{f_{0}}(t), \\
\dot{m}_{g}(t, L) & =\dot{m}_{g_{L}}(t), \\
\dot{T}_{g}(t, L) & =T_{g_{L}}(t) .
\end{aligned}
$$

The initial conditions for the gas and wall temperatures and working fluid enthalpy are given by $(z \in[0, L])$ :

$$
\begin{aligned}
& h_{f}(0, z)=h_{f_{\text {init }}}(z), \\
& T_{\text {wall }_{\text {int }}}(0, z)=T_{\text {wall }_{\text {int }} \text { init }}(z), \\
& T_{g}(0, z)=T_{g_{\text {init }}}(z), \\
& T_{\text {wall }_{\text {ext }}}(0, z)=T_{\text {wall }_{\text {ext }} \text { init }}(z),
\end{aligned}
$$

\section{Heat transfer and pressure drop}

To model the convection from the transfer fluid to the pipe walls and from the internal pipe to the working fluid, a heat transfer coefficient $(\alpha)$ is needed. The convection from a boundary to a moving fluid is usually represented by the dimensionless number Nusselt $(N u)$ which is the ratio of convective to conductive heat transfer.

$$
N u(\alpha)=\frac{\alpha l}{\lambda},
$$

where $l$ represents a characteristic length and is, in this case, the hydraulic diameter. Numerous correlations to approach this number can be found in the literature and are usually derived from experiments, see for example [33]. In single phase, the Gnielinski correlation is chosen for both fluids. In two phase, Chen (for evaporation) and Shah (for condensation) correlations are used. Pressure drop in both fluids are taken into account in order to simulate the real performance of the system. The pressure drop can be split into three main contributors:

$$
\Delta P=\Delta P_{\text {static }}+\Delta P_{\text {momentum }}+\Delta P_{\text {friction }},
$$

where the static pressure drop $\left(\Delta P_{\text {static }}\right)$ is function of the change in static head (i.e. the height), the momentum pressure drop $\left(\Delta P_{\text {momentum }}\right)$ depends 
on the change on density during phase change and the friction contribution $\left(\Delta P_{\text {friction }}\right)$ is function of the speed of the fluid and the considered geometry. Table 2 shows the different correlations used depending on flow conditions. In laminar single phase, the assumption of a constant heat flux at the wall is made.

\begin{tabular}{llcc}
\hline & & Laminar & Turbulent \\
\hline \multirow{3}{*}{ Heat transfer } & Single phase & Nu $=4.36$ & Gnielinski \\
\cline { 2 - 4 } & Two phase evaporation & Chen & Chen \\
\cline { 2 - 4 } & Two phase condensation & Shah & Shah \\
\hline Pressure drop & Single phase & Poiseuille & Blasius \\
\cline { 2 - 4 } & Two phase & Friedel & Friedel \\
\hline
\end{tabular}

Table 2: Correlations used in HEX

\subsubsection{Valve(s)}

The fluid flow $\dot{m}$ through the valve is modeled using a compressible valve equation of the form:

$$
\dot{m}_{f_{i n, v}}=C_{d_{v}} S_{e f f_{v}} \sqrt{\rho_{f_{i n, v}} P_{f_{i n, v}} \phi}
$$

where the compressibility coefficient $\phi$ is defined as:

$$
\phi=\frac{2 \gamma_{f}}{\gamma_{f}-1}\left(\varphi^{\frac{2}{\gamma_{f}}}-\varphi^{\frac{\gamma_{f}+1}{\gamma_{f}}}\right),
$$

with

$$
\varphi=\left\{\begin{aligned}
\frac{P_{f_{\text {out }, v}}}{P_{f_{i n, v}, v}} & \text { if } \frac{P_{f_{\text {out }, v}}}{P_{f_{\text {in }, v}}}>\frac{2}{\gamma_{f}+1} \frac{\gamma_{f}}{\gamma_{f}-1} \\
\frac{2}{\gamma_{f}+1}{ }^{\frac{\gamma_{f}}{\gamma_{f}-1}} & \text { if } \frac{P_{f_{\text {out }, v}}}{P_{f_{\text {in }, v}}} \leq{\frac{2}{\gamma_{f}+1}}^{\frac{\gamma_{f}}{\gamma_{f}-1}}
\end{aligned}\right.
$$

where $\gamma_{f}$ is the ratio of the specific heats of the working fluid and depends on the temperature and the pressure. Equation (23) means that the parameter $\varphi$ is either the pressure ratio if the flow is subsonic or the critical pressure ratio when the flow is supersonic. 


\subsubsection{Expansion machine}

Several studies have been carried out in order to choose the correct expansion machine for Rankine based recovery system [34, 35. In most of them where vehicle installation is considered, turbine expanders are preferred for their compactness and their good performance [8, 36] since the major advantage of volumetric expander such as piston machines is the expansion ratio 37. Though, recent study [38] has shown turbine with expansion ratio over 40:1 on a single stage with really good performance at tolerable speed for a vehicle installation. In this study, only a kinetic expander is modeled. The turbine nozzle is represented by the following equation:

$$
\dot{m}_{f_{i n, e x p}}=K_{e q} \sqrt{\rho_{f_{i n, e x p}} P_{f_{i n, e x p}}\left(1-{\frac{P_{f_{i n, e x p}}}{P_{f_{o u t, e x p}}}}^{-2}\right)} .
$$

And the isentropic efficiency is calculated according to the following relation:

$$
\eta_{\exp _{i s}}=\eta_{\exp _{i s_{\max }}}\left(\frac{2 c_{u s}}{c_{u s_{\max }}}-{\frac{c_{u s}}{c_{u s_{\max }}}}^{2}\right),
$$

where

$$
c_{u s}=\frac{u}{c_{s}}=\frac{\omega_{\exp } R_{e x p}}{2 \sqrt{h_{f_{i n, e x p}}-h_{f_{i n, e x p} p_{i s}}}} .
$$

Model parameters are fitted using data from supplier and similarity relation [39].

\subsubsection{Other heat exchanger(s)}

In order to describe the vehicle cooling system, the number of transfer unit (NTU) approach is used. It is commonly adopted when it comes to single phase heat exchanger modeling. For an air cooled radiator the following relations are used:

$$
\dot{Q}_{a i r}=\dot{m}_{a i r} c_{p_{a i r}} \varepsilon\left(T_{\text {coolant }_{i n}}-T_{a i r_{i n}}\right) .
$$

For a given geometry, $\varepsilon$ can be calculated using correlations based on the heat capacity ratio. By considering parallel flow configuration for the radiators, 
the effectiveness can be written:

$$
\begin{aligned}
\varepsilon & =\frac{\left.1-e^{-N T U\left(1+\frac{\left(\dot{m} c_{p}\right)_{\min }}{\left(\dot{m} c_{p}\right)_{\max }}\right.}\right)}{1+\frac{\left(\dot{m} c_{p}\right)_{\min }}{\left(\dot{m} c_{p}\right)_{\max }}}, \\
\text { with } N T U & =\frac{U A}{\left(\dot{m} c_{p}\right)_{\min }} .
\end{aligned}
$$

\subsubsection{Coolant pump and fan}

The coolant pump model used is a map-based model function of engine speed and pressure rise. This one is sized to deliver enough subcooling even at high engine load. The engine fan is also a map-based model delivering a given mass flow at a given speed. The fan consumption is calculated according to:

$$
\dot{W}_{\text {fan }}=C_{\text {fan }} \rho_{\text {air }} N_{\text {eng }} G_{\text {ratio }} N_{\text {fan }}^{2},
$$

where the coefficients $C_{f a n}$ and $G_{\text {ratio }}$ are dependent on the fan model and vehicle. The mass flow rate blown by the fan is mapped according to data from supplier and depends on the fan speed and atmospheric conditions. The air mass flow rate going through the cooling package $\left(\dot{m}_{\text {air }}\right)$ is a combination of the natural air mass flow rate (corresponding to a fraction of the vehicle speed) and the forced mass flow rate (corresponding to the mass flow blown by the fan).

$$
\dot{m}_{\text {air }}=\rho_{\text {air }} A_{\text {cool pack }} S r_{\text {air }} V_{\text {vehicle }}+\dot{m}_{\text {fan }}\left(N_{\text {fan }}, \rho_{\text {air }}\right),
$$

where $S r_{a i r}$ is the ratio between the vehicle speed and the air speed in front of the cooling package and is either calculated via computational fluid dynamics (CFD) or measured in a wind tunnel.

\section{SYSTEM OPTIMIZATION}

\subsection{Key aspects}

In this section, the degrees of freedom used to optimize the WHRS are detailed: 
1. Fluid choice: the fluid selection is a critical part of the system optimization. The correct fluid choice has to match both heat source and cold sink in order to generate as much power as possible [40, 41]. From environmental and legal points of view, the working fluid has to respect:

- Its chemical class: chlorofluorocarbons (CFCs) have been banished by the Montreal Protocol and hydrochlorofluorocarbons (HCFCs) production is planned to be phased out by 2030 .

- Its presence on the global automotive declarable substance list (GADSL).

- Its chemical properties such as the global warming potential (GWP), the ozone depletion potential (ODP) or the risk phrases (R-phrases).

- Its classification according the national fire protection agency (NFPA) 704 classification (ranking above 1 in Health or Instability class)

In top of that, the freezing point which has to be below $0{ }^{\circ} \mathrm{C}$.

2. Components choice and design: the correct choice of components and particularly the expansion machine have an important impact on the system performance and the control design. Indeed, a volumetric expander is less stringent in terms of degree of superheat and tolerate a given amount of liquid during the expansion process whereas a kinetic expander requires a higher degree of superheat in order to have a full vapor expansion (liquid droplets can cause blade erosion and broke the machine). The design of all other components of the Rankine system is also critical to maximize its potential. For example, too big heat exchangers show higher performance but also inertia which could be a disadvantage when coming to highly dynamic driving cycle since the more interesting points (i.e. high load engine operating points) are not lasting for long. A heavy evaporator is therefore not catching up the maximum potential of this high heat flow rate.

3. Heat sources and sinks arrangement: the architecture of sources and sinks has to be adapted to increase overall performance. Heat sources choice and arrangement impact a lot the system performance by changing the heat input to the system. The cold sinks choice is influencing the condensing pressure so the overall pressure ratio (and therefore the power generated by the expander). 
4. Other system interactions: as the final goal is to implement the system in a heavy duty vehicle, the WHRS must be considered not as a standalone system but as a connected sub system of the complete vehicle. The interactions of the Rankine system on the other sub-systems have to be taken into account (e.g. increase in fan consumption due to the heat rejection coming from the condenser).

\subsubsection{Investigated architectures and components}

Several studies have been conducted in the field of waste heat recovery Rankine based systems for mobile applications. A screening of the different heat sources available is reported in [5] and shows that the most promising ones are the EGR and the Exhaust streams. In the present study, only these two heat sources are considered since they present the higher grade of temperatures among other sources. Therefore four different Rankine layout are studied:

1. Exhaust recovery only where the only heat source are the exhaust gases.

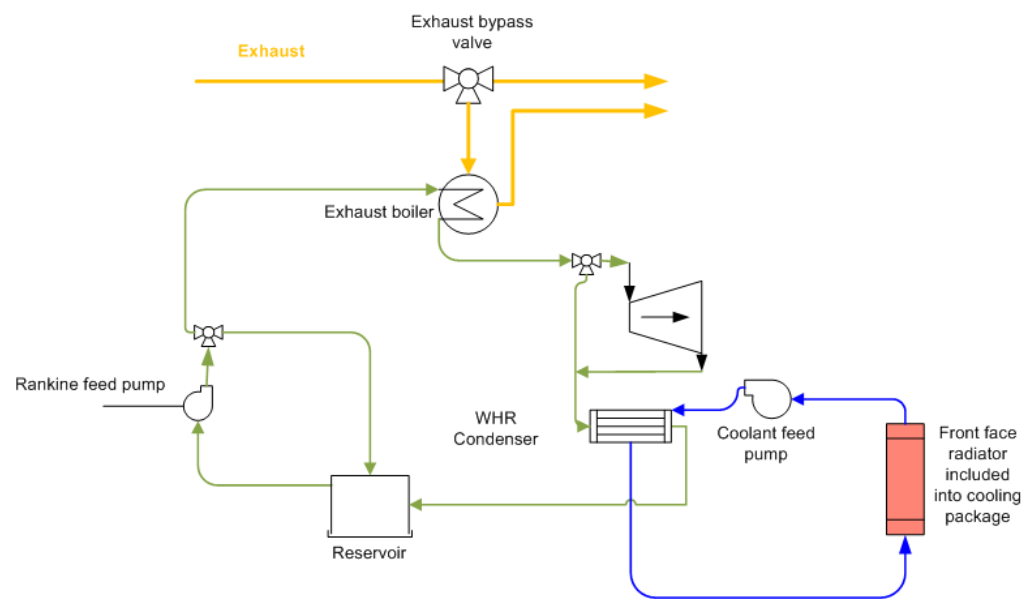

Figure 3: Exhaust only system schematic

2. EGR recovery only where only the EGR gases are used as the only heat source. 


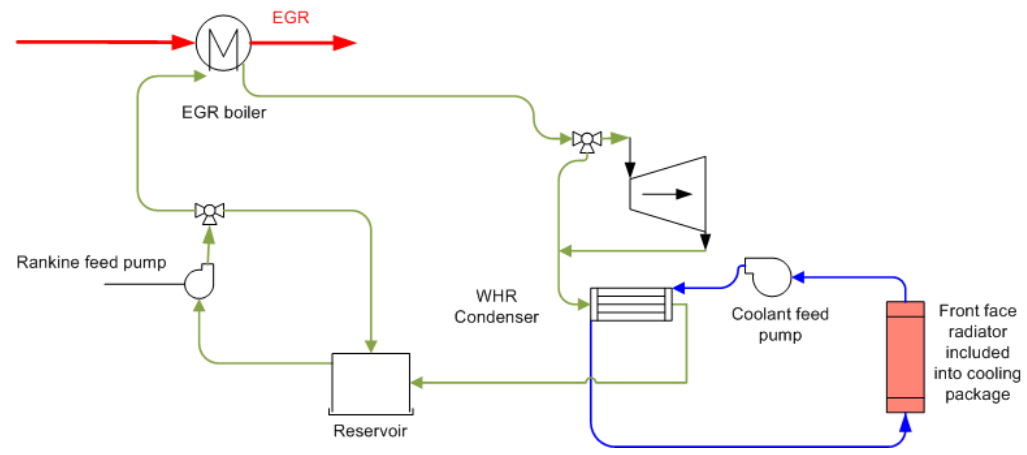

Figure 4: EGR only system schematic

3. Both sources in parallel where the working fluid is split into two streams heated up separately by each source and then mixed before the expander.

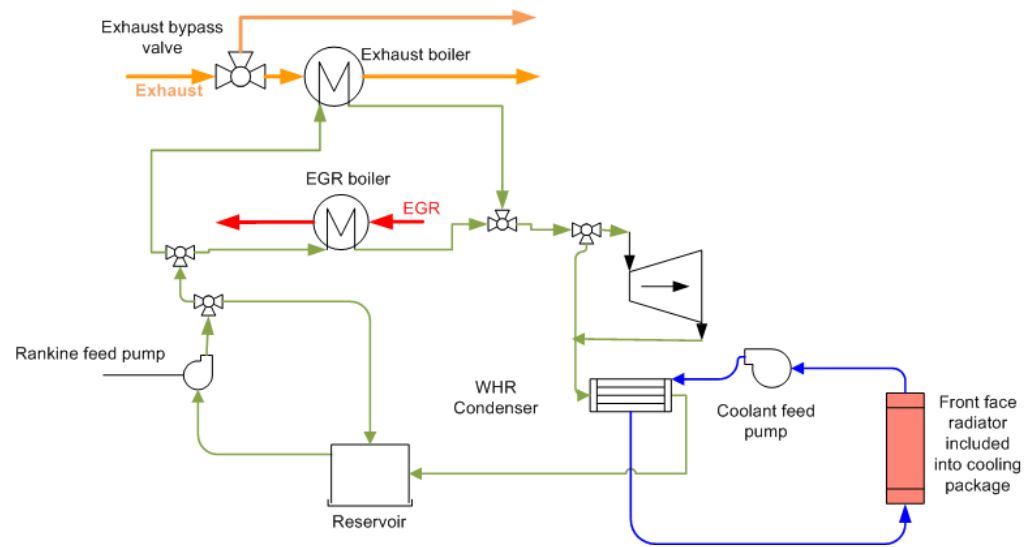

Figure 5: Exhaust and EGR in parallel system schematic

4. EGR and exhaust in series where the EGR gases are used to preheat the fluid and the exhaust gases to vaporize and superheat. Using the EGR as a preheater, instead of a superheater, is chosen to lower the EGR gases temperature after the evaporation process. 


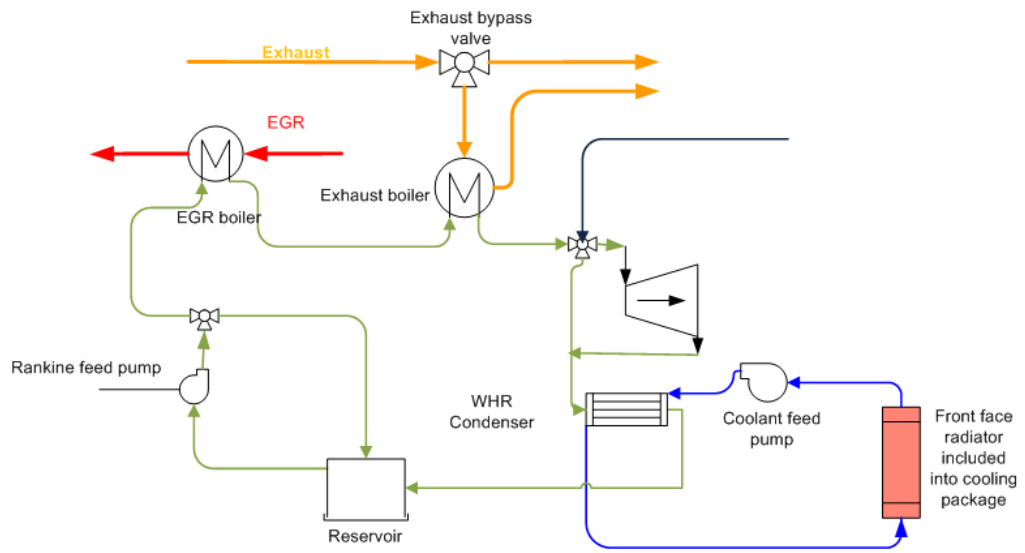

Figure 6: Exhaust and EGR in series system schematic

Coupled to that, two different cooling architecture are approached:

- A first one (called in the following Cooling Config 1) which uses a low temperature radiator dedicated to the Rankine condenser and is placed between the charge air cooler $(\mathrm{CAC})$ and the engine radiator.

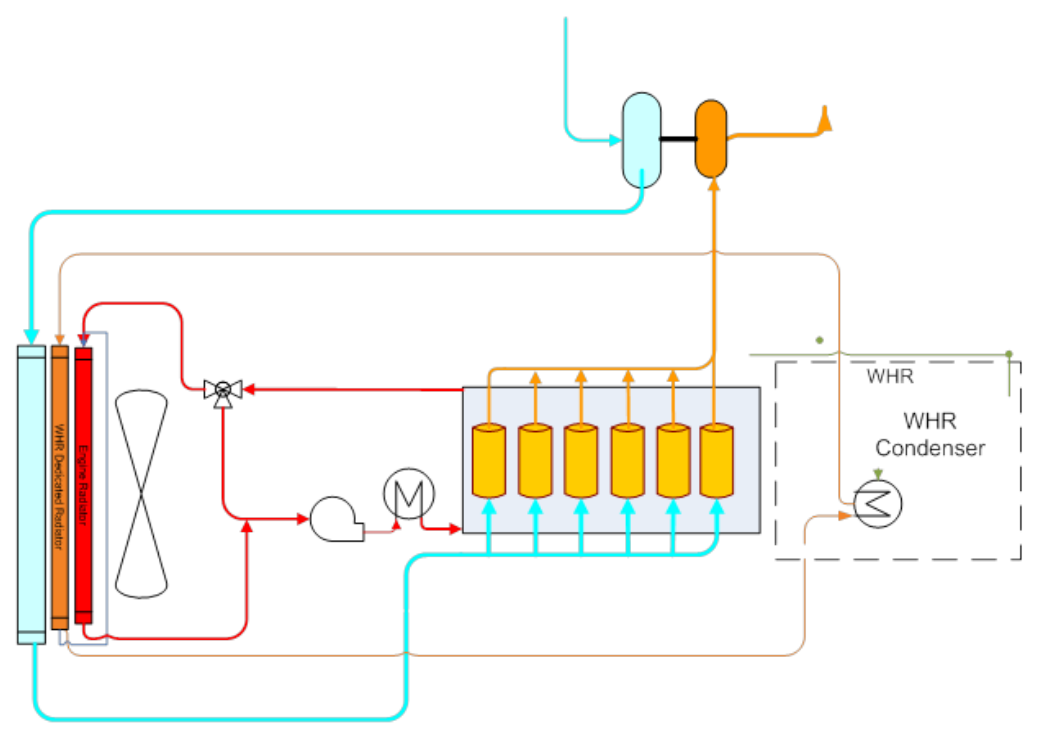

Figure 7: Cooling config 1

- A second one (called in the following Cooling Config 2) using the engine 
coolant as heat sink for the Rankine cycle. In that case, a derivation of the coolant is done in front of the engine to benefit from the lowest temperature grade.

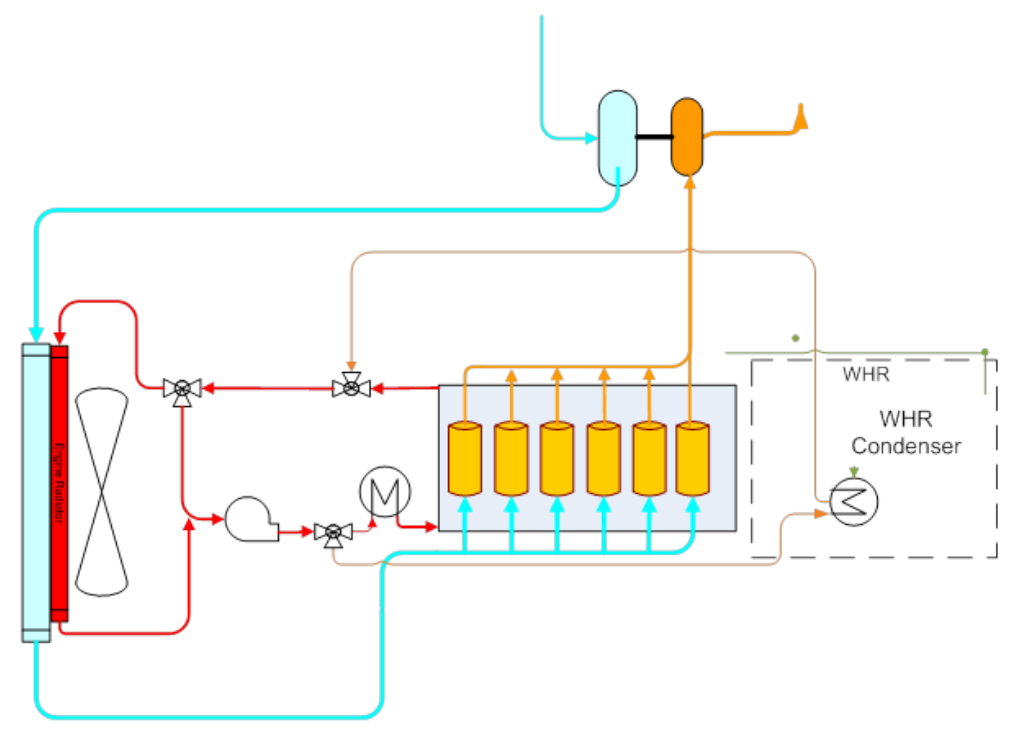

Figure 8: Cooling config 2

Concerning the components, as previously said, the study is limited to one expansion machine technology: turbine expander. For the heat exchangers (evaporator(s) and condenser), only counter-current configurations which are usually used in this kind of applications [42] are considered.

\subsection{Duty cycles}

Driving conditions are acting as input disturbances and therefore, their impact on the target performance must be studied with care.

\subsubsection{Steady state evaluation}

Under steady state driving conditions, the performance is evaluated by expressing the weighted average net output power of the 1D model (3.3) (the NOP, which is the additional power that the engine receives, therefore corresponds to the fuel economy) on 13 engine operating points (summarized 


\begin{tabular}{|c|c|c|c|c|c|c|c|}
\hline & Name & $\begin{array}{c}\text { Vehicle } \\
\text { speed }\end{array}$ & $\begin{array}{l}\text { EGR } \\
\text { mass } \\
\text { flow }\end{array}$ & $\begin{array}{c}\text { EGR } \\
\text { tempe- } \\
\text { rature }\end{array}$ & $\begin{array}{c}\text { Exhaust } \\
\text { mass } \\
\text { flow }\end{array}$ & $\begin{array}{c}\text { Exhaust } \\
\text { tempe- } \\
\text { rature }\end{array}$ & $\begin{array}{l}\text { Weight } \\
\text { factor }\end{array}$ \\
\hline & Parameter & $V_{\text {vehicle }}$ & $\dot{m}_{e g r}$ & $T_{e g r_{0}}$ & $\dot{m}_{e x h}$ & $T_{e x h_{0}}$ & $w_{i}$ \\
\hline & Unit & $\mathrm{km} / \mathrm{h}$ & $g / s$ & ${ }^{\circ} \mathrm{C}$ & $g / s$ & ${ }^{\circ} \mathrm{C}$ & $\%$ \\
\hline 1 & & 20 & 31.5 & 263.1 & 78.7 & 237.9 & 6.9 \\
\hline 2 & & 85 & 38 & 409.5 & 119.8 & 338.2 & 9.0 \\
\hline 3 & & 60 & 59.5 & 635.0 & 309.3 & 443.9 & 4.9 \\
\hline 4 & & 85 & 54.6 & 544.0 & 252.4 & 413.0 & 2.6 \\
\hline 5 & & 75 & 46.1 & 454.0 & 154.6 & 366.4 & 18.9 \\
\hline 6 & & 85 & 56.3 & 247.5 & 85.7 & 212.5 & 10.5 \\
\hline 7 & & 30 & 85.9 & 631.0 & 352.7 & 425.1 & 2.8 \\
\hline 8 & & 85 & 69.4 & 562.5 & 290.5 & 405.5 & 3.6 \\
\hline 9 & & 50 & 58 & 473.0 & 183.2 & 336.2 & 12.7 \\
\hline 10 & & 85 & 59.8 & 251.0 & 95.2 & 216.0 & 11.2 \\
\hline 11 & & 45 & 87.1 & 581.0 & 326.8 & 400.8 & 2.3 \\
\hline 12 & & 75 & 68.9 & 472.0 & 198.4 & 359.6 & 10.7 \\
\hline 13 & & 85 & 62.9 & 252.5 & 102.8 & 217.5 & 3.9 \\
\hline
\end{tabular}

Table 3: Steady state evaluation: Driving conditions and weight for 13 engine operating points

in table 3) These operating points are chosen to represent a classical long haul driving cycle and weighted according to the percentage of energy used on each operating point. Operating point number 5 is identified as the designing point whereas the operating points 3 and 11 are considered critical due to the high engine load and the low vehicle speed.

\subsubsection{Dynamic evaluation}

In order to accurately assess the potential of the WHRS, dynamic driving cycles are also used to complete the study and check whether the performance found with the previous method is correct. This is really important when coming to thermal systems performance estimation since they generally have long response time [43]. The driving cycle used is split into 7 phases (summarized in table 4) supposed to represent all conditions of a long haul truck usage. In the previous 1D model (3.3), each phase is considered, in the rest of the study, as a driving cycle of approximately the same length (denoted by 


\begin{tabular}{lccccccc}
\hline Driving cycle & 1 & 2 & 3 & 4 & 5 & 6 & 7 \\
\hline Road Type & $\begin{array}{c}\text { Extra } \\
\text { urban }\end{array}$ & Highway & Highway & $\begin{array}{c}\text { Extra } \\
\text { urban }\end{array}$ & $\begin{array}{c}\text { Extra } \\
\text { urban }\end{array}$ & $\begin{array}{c}\text { Extra } \\
\text { urban }\end{array}$ & Rolling \\
\hline Vehicle speed & Medium & High & Medium & Low & Medium & High & High \\
\hline Weight factor $w_{i}(\%)$ & 10 & 10 & 50 & 7.5 & 10 & 7.5 & 5 \\
\hline
\end{tabular}

Table 4: Dynamic evaluation: Driving conditions and weight for the 7 phases

a number from 1 to 7 ) and weighted according to their real life importance (for a long haul truck highway is predominant).

\subsection{System performance evaluation}

The criterion used for the performance evaluation under steady state and dynamic driving conditions, is the total net reinjected power to the conventional driveline. This is done by taking into account the producer (WHRS expander) and different consumers (cooling fan, WHRS pump and WHRS coolant pump) and assuming them to be mechanically driven (this is not always true for the pumps but efficiencies are detuned to take into account the mechanical to electrical conversion). A complete vehicle model integrating engine, exhaust after treatment system (EATS), transmission, cooling package, WHRS and road environment is used to simulate the total vehicle approach and calculate the power needed to drive the vehicle. The performance criterion $(P C)$ is then calculated as the ratio of this reinjected power to the engine power:

$$
P C_{i}=\int_{t_{\text {init }}}^{t_{\text {final }}} \frac{\dot{W}_{\text {exp }}-\dot{W}_{\text {pump }}-\dot{W}_{\text {cool }, \text { pump }}-\dot{W}_{\text {fan }}}{\dot{W}_{\text {eng }}},
$$

where the engine power $\left(\dot{W}_{\text {eng }}\right)$ taking into account the mechanical auxiliaries consumption mounted on it and the increase in exhaust backpressure (due to the exhaust evaporator). The vehicle gross weight is assumed constant and equal to 36 tons which intends to represent the average load on a long haul truck. The performance criterion $(P C)$ over the different steady state operating points or driving cycles is then calculated by summing the weighted $P C$ on each points/cycles:

$$
P C=\sum_{i=1}^{k} w_{i} P C_{i}
$$


where $k \in\left[\begin{array}{ll}1 & 13\end{array}\right]$ for steady state evaluation (presented in section 4.2.1) and $k \in\left[\begin{array}{ll}1 & 7\end{array}\right]$ for evaluation on dynamic driving cycle (presented in section 4.2.2).

\section{RESULTS AND DISCUSSION}

\subsection{D model validation}

In this section some component models, judged as critical for the overall system performance evaluation, are first validated thanks to supplier or experimental data. The different studied configurations being made of the same components model it has been decided to validate the models components by components. The validation is done by comparing experimental to the modeling results. A model is further considered as valid if the average modeling error is below $5 \%$ of the predicted quantity. Since the main dynamic of the system is contained in the evaporators [43] and the final aim is to predict the power generated by the system only validation figures are presented for the evaporators and the expansion machine. It should be said that a more detailed validation on the whole system mounted on the vehicle should be carried out but this requires the system to be built. Unfortunately this technology is still under investigation at the truck makers level and no figures are available yet. This study intends then to compare the architecture and analyze their impact on the truck fuel consumption.

\subsubsection{Heat exchangers}

A high attention is paid to the evaporators in order to accurately predict the steady state and dynamic performance of those components (corresponding to the model presented in section 3.3.3). In this paper, a finite volume approach has been chosen to implement the continuous set of equations (equations 6, 7, 8, 9). Figure 9 shows the schematic of the discretized model. Table 5 and 6 show respectively steady state and dynamic prediction errors. Note that in both cases the relative error is computed according to the maximum temperature difference between the heat exchanger bounds (usually $\left.T_{g_{L}}-T_{f_{0}}\right)$. The steady state validation is conducted on a lot of operating conditions supposed to represent the complete range of operation for those components. The dynamic behavior is evaluated on different load point variations but obviously need further validation especially on fast change that can 


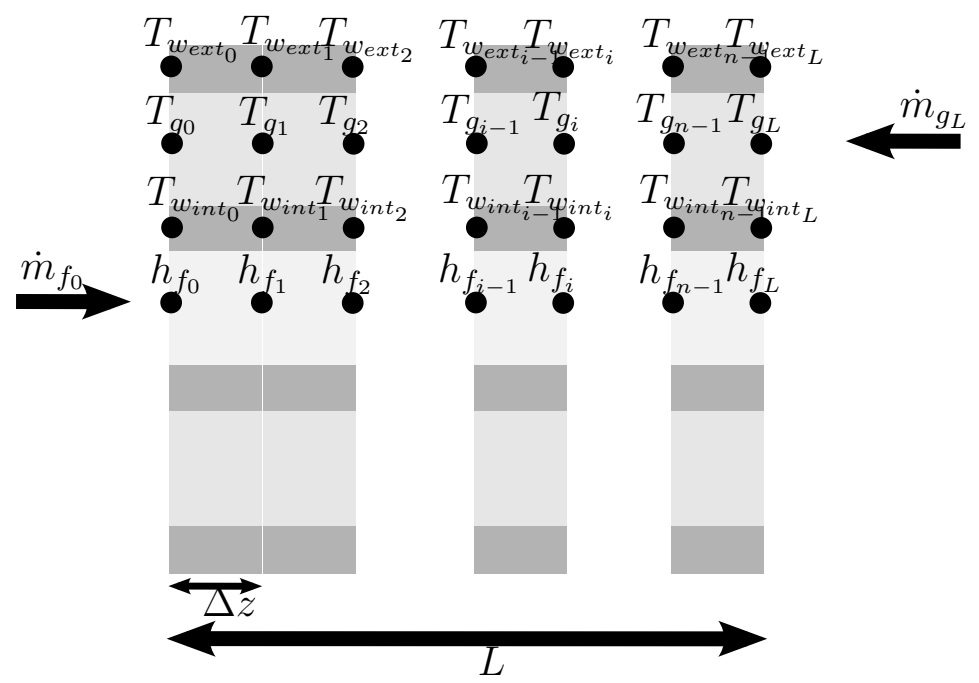

Figure 9: HEX model schematic

416

take place on real driving conditions. However, the mean relative modeling error remains lower than $3.5 \%$, which is considered acceptable.

\begin{tabular}{lcccccccc}
\hline & \multicolumn{2}{c}{$T_{f_{L_{E G R B}}}$} & \multicolumn{2}{c}{$T_{f_{L_{E x h B}}}$} & \multicolumn{2}{c}{$T_{\text {egr }_{0}{ }_{E G R B}}$} & \multicolumn{2}{c}{$T_{e h_{0_{E x h B}}}$} \\
\hline Error & $\max$ & mean & $\max$ & mean & $\max$ & mean & max & mean \\
\hline Absolute (K) & 2.95 & 1.30 & 9.15 & 4.16 & 7.54 & 2.54 & 15.47 & 4.71 \\
\hline Relative (\%) & 0.57 & 0.29 & 8.84 & 3.28 & 2.34 & 0.61 & 8.61 & 3.40 \\
\hline
\end{tabular}

Table 5: Evaporators steady state validation

\begin{tabular}{lcccccccc}
\hline & \multicolumn{2}{c}{$T_{f_{L_{E G R B}}}$} & \multicolumn{2}{c}{$T_{f_{L_{E x h B}}}$} & \multicolumn{2}{c}{$T_{\text {egr }_{0}{ }_{E G R B}}$} & \multicolumn{2}{c}{$T_{\text {exh }_{0_{\text {Exh }}}}$} \\
\hline Error & $\max$ & mean & $\max$ & mean & $\max$ & $\operatorname{mean}$ & $\max$ & mean \\
\hline Absolute (K) & 4.5 & 1.5 & 25.9 & 2.3 & 7.9 & 2.8 & 20 & 4.2 \\
\hline Relative (\%) & 1.38 & 0.46 & 14.37 & 1.28 & 2.43 & 0.86 & 11.1 & 2.33 \\
\hline
\end{tabular}

Table 6: Evaporators dynamic validation

\subsubsection{Expansion machine}

The turbine expander model presented in 3.3.5 is fitted thanks to supplier data. Figure 10 and 11 respectively show the working fluid inlet pressure and the generated power predicted by the model versus the normalized working 


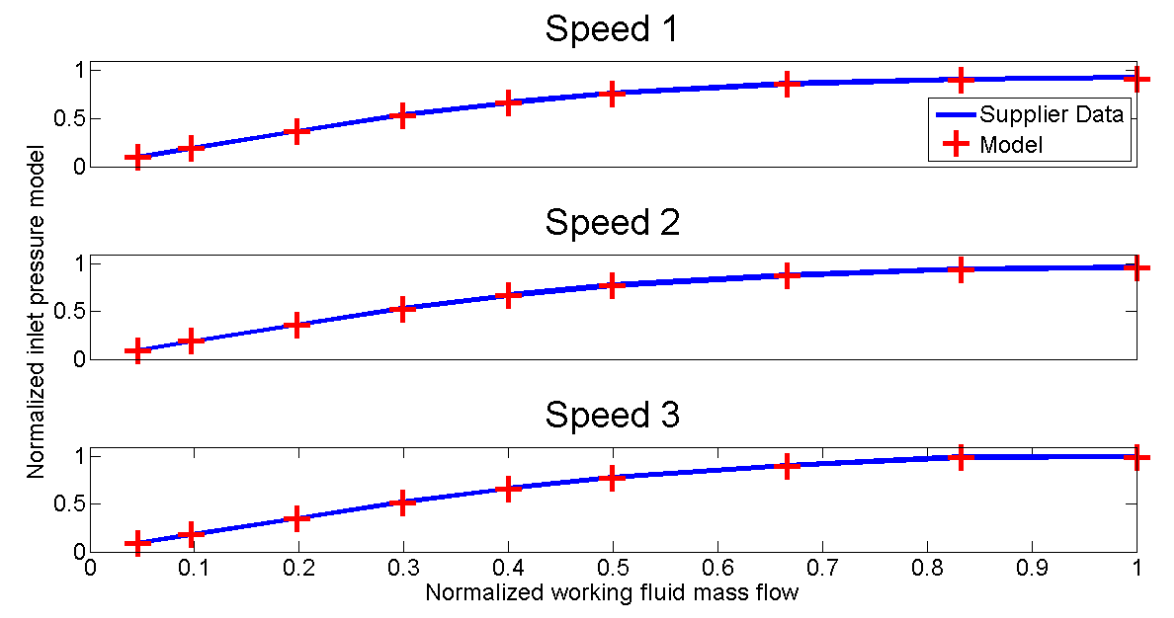

Figure 10: Turbine pressure model validation

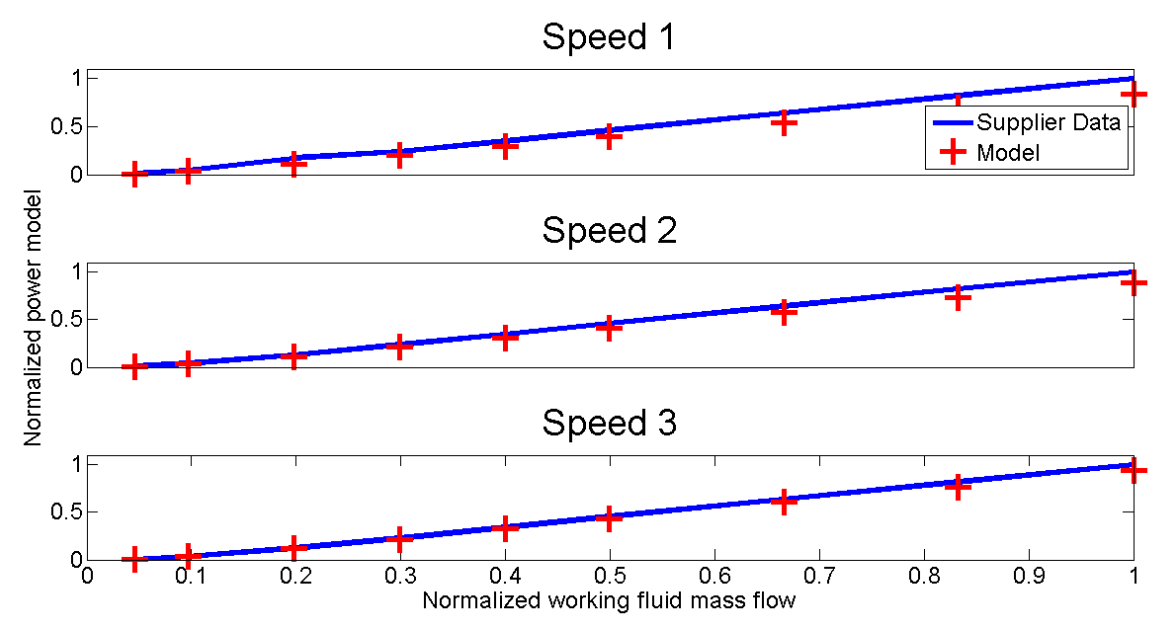

Figure 11: Turbine power model validation

fluid mass flow entering in the turbine. Those two quantities are well fitted and this model is further considered validated.

\subsubsection{Model analysis}

The whole 1D models are built from the same component models. The inertial effect of the pipes are neglected since their effect are negligible compared 
to the other components dynamics (namely the evaporators) [43]. The full model is then a combination of validated detailed models (e.g. heat exchangers) and quasi-static models (pumps expansion machine and fan) used for comparison purpose. This study then intends to compare the different heat sources and sinks configurations possible on a heavy duty vehicle to select the best system in terms of performance.

\subsection{Optimization of the WHRS}

\subsubsection{Working fluid selection}

From an exhaustive fluid list [25], all those that do not respect the different criteria mentioned in 4.1 have been removed. However, as water is a good reference fluid since it is generally used in power plant [44, it has been kept. The results presented hereafter are coming from the ideal thermodynamic 0D model presented in section 3.2 where all 13 operating points are simulated for two condensing temperatures $60^{\circ} \mathrm{C}$ and $90^{\circ} \mathrm{C}$, which intends to represent the two cooling configurations presented in the previous section. The parameters of the cycle, $P_{f_{\text {out }, \text { pump }}}$ and $\dot{m}_{f}$ are optimized to reach the highest performance (i.e. maximize the $N O P$ ). Here, each hot stream is simulated separately in order to see the impact of the heat source on the Rankine fluid selection. The simulation matrix contains 13 operating points (listed in section 5.2.2) and 13 selected working fluids. For the sake of simplicity, the results presented in figure 12 show the number of occurrences where the fluid is in the top five 1 regarding the NOP. When analyzing each operating point and configuration separately among the $13 \times 13$ simulations, water is the best fluid for heavily loaded operating points. For low and medium engine load, as gases temperatures are lower and due to the large enthalpy of vaporization of water and the high level of superheating required, it is not recommended to use it. Acetone and ethanol show good performance at mid and high engine load no matter of the cold sink temperature. Refrigerants such as R1233zd or Novec 649 show good results for heat source temperature under $280{ }^{\circ} \mathrm{C}$ for the lowest condensing temperature. More exotic fluids such as cis-butene or MM (silicon oil) could be attractive for low and medium engine load respectively at $60^{\circ} \mathrm{C}$ condensing temperature for the first one and $90^{\circ} \mathrm{C}$ for the second one.

\footnotetext{
${ }^{1}$ top five means the $N O P$ related to the fluid is ranked in one of the five first position
} 


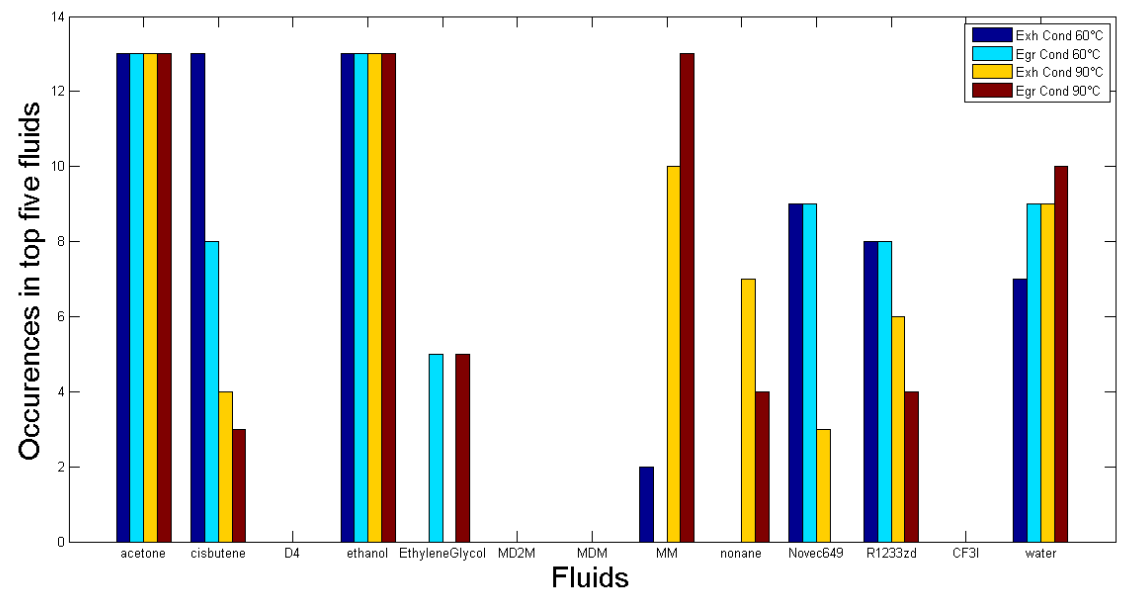

Figure 12: Number of occurrences of each fluid in top five $\mathrm{I}_{\text {for }}$ different boundary conditions

These first simulations results limit the number of investigated working fluids for the remaining part of this paper to the following ones: Acetone, Ethanol. Those two fluids represent the highest number of occurrences for the different configurations considered. As these fluids have similar volumetric flows it would be possible to use the same components' characteristics with only some minor changes (e.g. throat diameter for the turbine model and pump displacement). However due to the low flash point of Acetone $\left(-20^{\circ} \mathrm{C}\right)$ only ethanol is then considered suitable for a mobile application.

\subsubsection{Steady state performance analysis}

Now, the performance criterion is analyzed on the 13 operating points and the 2 cooling architectures (Cooling config 1 and 2) for the previously chosen working fluids. The savings are computed thanks to the weight factors presented in table 3 . Figure 13 presents the NOP to engine power ratio evaluated for the 2 cooling configurations. It can be observed that the decrease due to higher condensing temperatures induced by cooling configuration 2 is somehow constant (between 11 and $15 \%$ ) no matter of the Rankine cycle arrangement. This drop in performance is due to the increase in condensing pressure which affects the overall pressure ratio through the expansion machine and therefore its performance. This could be partially balanced by a 

cost of ownership.

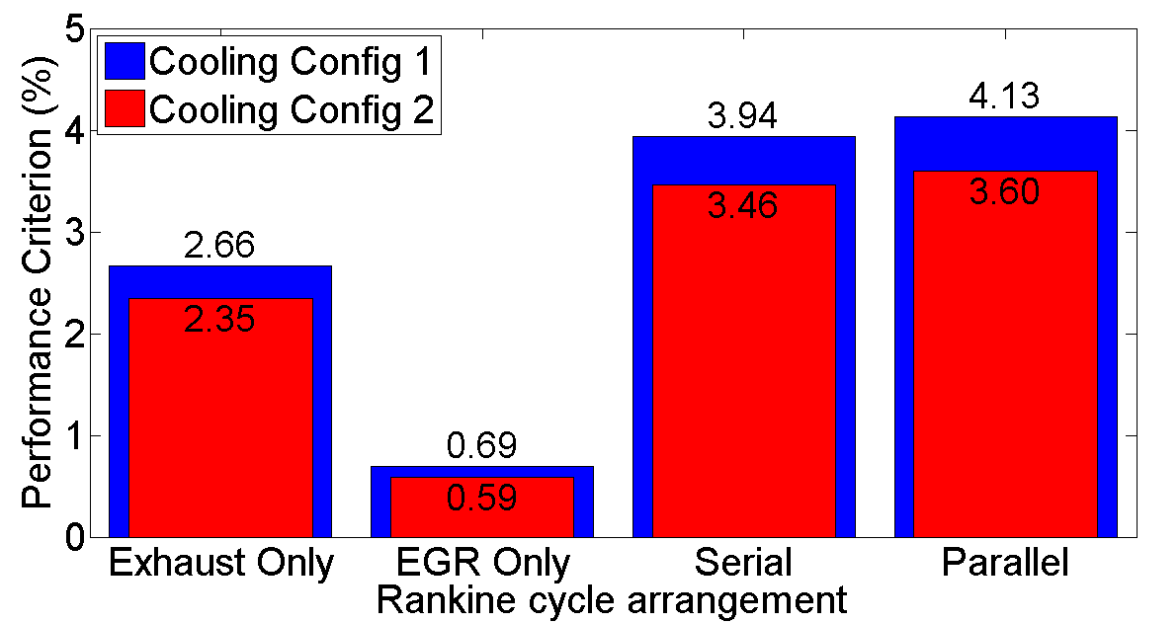

Figure 13: Steady state $P C$ assessment 


\subsubsection{Dynamic performance analysis}

Then, in order to validate the previously used method, dynamic simulations are run to further assess the performance criterion of the WHRS. Indeed, as previously said, the Rankine based recovery systems could have long time constant due to the boiler(s) inertia (wall capacity). This could help in terms of control by filtering some high transient of the heat sources but reduce the heat transferred to the fluid, since only a fraction of the heat contained in the hot gases is then used. In the following, the performance is assessed on 7 different driving cycles (see table 4) representative of a long haul truck usage. An example of two of those road profiles is presented in fig 14. Each
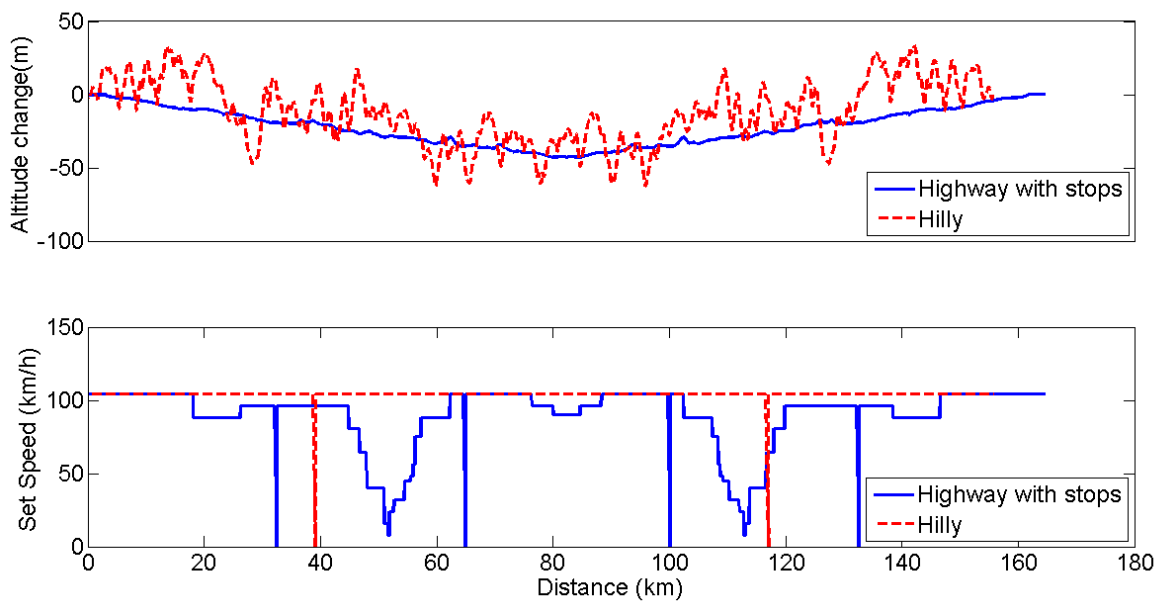

Figure 14: Road profiles examples

driving cycle is simulated separately starting from ambient conditions that can result in a lower $P C$ due to the long warm up time of the exhaust after treatment system. Weights (see 4) are applied to the different driving cycles to calculate the total performance criterion of the WHRS.

Figures 15 and 16 show the $P C$ reached by each Rankine configuration respectively for cooling configuration 1 and 2 . As shown is 5.2 .2 the decrease in performance using cooling configuration 2 rather than cooling configuration 1 is more or less constant and around $11 \%$. The main information brought by this study remains the lower fuel savings when simulating the system in dynamic instead of steady state, which can be as big as $50 \%$ for the systems using exhaust as heat source. This is due to two main reasons: 
- the exhaust after treatment system, which has a very important constant time, causes big temperature drop during fast highly loaded engine conditions where a lot of heat is supposed to be available.

- the non optimal design of the tailpipe boiler used in the simulation model. Indeed the validation of the model shown in section 5.1 is based on prototypes components that do not represent the optimum in terms of size and transient performance.

- the constraint implemented on the EGR temperature at the evaporator outlet not to derate the emission control. The maximum EGR temperature is set to $150{ }^{\circ} \mathrm{C}$ which on some phases is not going hand in hand with the superheat level control. The EGR temperature becomes the control objective and when the superheat is not sufficient the expander is not fed with working fluid and therefore the power production is null.

Table 7 resumes the time (relative to the duty cylce time) where the superheat is sufficient to feed the expansion vapor. Systems recovering heat from the exhaust stream mainly suffer from a long start-up phase but then the system never lose the superheat level needed to expand the working fluid in the kinetic turbine. This long start-up is due to the boundary conditions used where all the sub-systems initial temperatures are set to ambient. For the system recovering heat only from the EGR the start-up is not significant since on some cycles the system is generating power more than $99 \%$ of the time (the EGR gets its normal operation temperature after few seconds whereas the thermal inertia of the EATS makes the temperature rise very slow). Nevertheless on highly loaded cycles (namely 3 and 7) the high engine load results into high EGR temperature and to not interact too much with the engine emissions system, the superheat is dropped to the detriment of the EGR temperature. Superheated vapor is no longer generated by the boiler and the fluid goes back to a diphasic state and the expansion machine is bypassed.

Anyway, similarly to the previous results in steady state, the best system in terms of fuel savings remains the EGR and exhaust in parallel with cooling configuration 1 that brings $2.2 \%$ savings on the overall weighted driving cycle. In addition to that, it can be seen that the relative performance are kept from arrangement to arrangement (compared to section 5.2.2). 


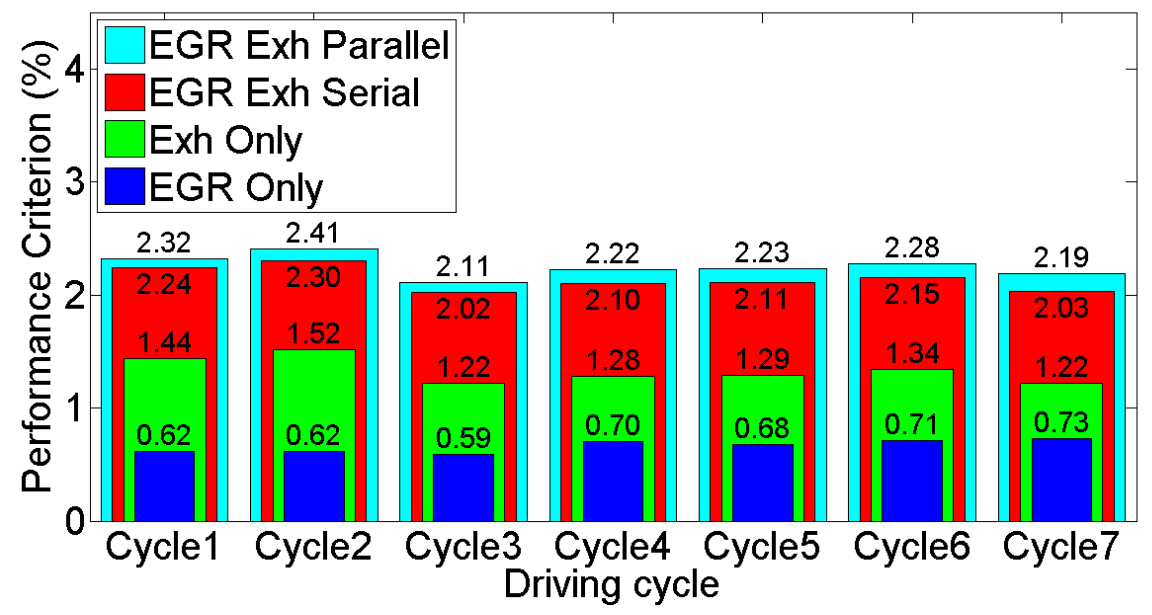

Figure 15: $P C$ for cooling configuration 1 over dynamic driving cycles

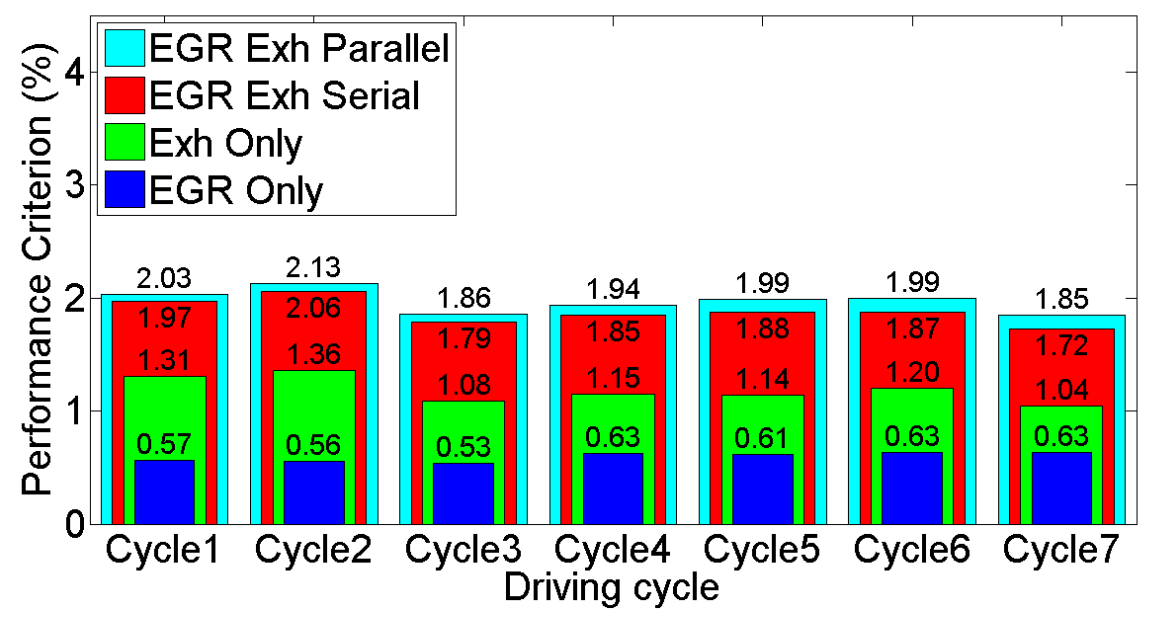

Figure 16: $P C$ for cooling configuration 2 over dynamic driving cycles 


\begin{tabular}{|c|c|c|c|c|c|}
\hline Driving cycle & Configuration & Exhaust & EGR & Serial & Parallel \\
\hline 1 & & $93.37 \%$ & $99.11 \%$ & $93.71 \%$ & $93.93 \%$ \\
\hline 2 & & $93.06 \%$ & $99.30 \%$ & $93.41 \%$ & $93.25 \%$ \\
\hline 3 & & $95.27 \%$ & $83.38 \%$ & $95.64 \%$ & $95.44 \%$ \\
\hline 4 & & $92.50 \%$ & $93.37 \%$ & $91.07 \%$ & $92.06 \%$ \\
\hline 5 & & $91.18 \%$ & $97.26 \%$ & $90.67 \%$ & $91.55 \%$ \\
\hline 6 & & $92.00 \%$ & $98.30 \%$ & $90.42 \%$ & $91.46 \%$ \\
\hline 7 & & $93.53 \%$ & $88.94 \%$ & $90.87 \%$ & $92.92 \%$ \\
\hline
\end{tabular}

Table 7: Vapor creation time ratios summary

\subsubsection{Optimal WHRS}

The low performance figures presented in the previous sections are mainly due to non optimized components for the considered application. In order to evaluate what could be the economy brought by an optimized system, the different components constituting the WHRS are redesigned to perfectly match the targeted application. In addition to that, a perfect insulation of these different components is then considered. In this section, only cooling configuration 1 is evaluated since it has been shown that it leads to larger savings. Both approaches previously used (steady state and dynamic analysis) are presented in figure 17. Optimization has been done on boilers and condenser size with respect with the additional weight. Pump and expansion machine performance are increased to reach standards in power plant Rankine cycles $\left(\eta_{\text {pump }_{i s}}=70 \%\right.$ and $\left.\eta_{\text {exp }_{i s, \max }}=78 \%\right)$. More acceptable results are reached for a vehicle implementation of such a system, especially when considering a system recovering from both EGR and exhaust in parallel. Again, a big step is observed between the two evaluation methodologies which tends to prove that the cycle division into a certain number of steady state engine operating points is not adapted for performance evaluation of thermal systems which generally have a long response time. 


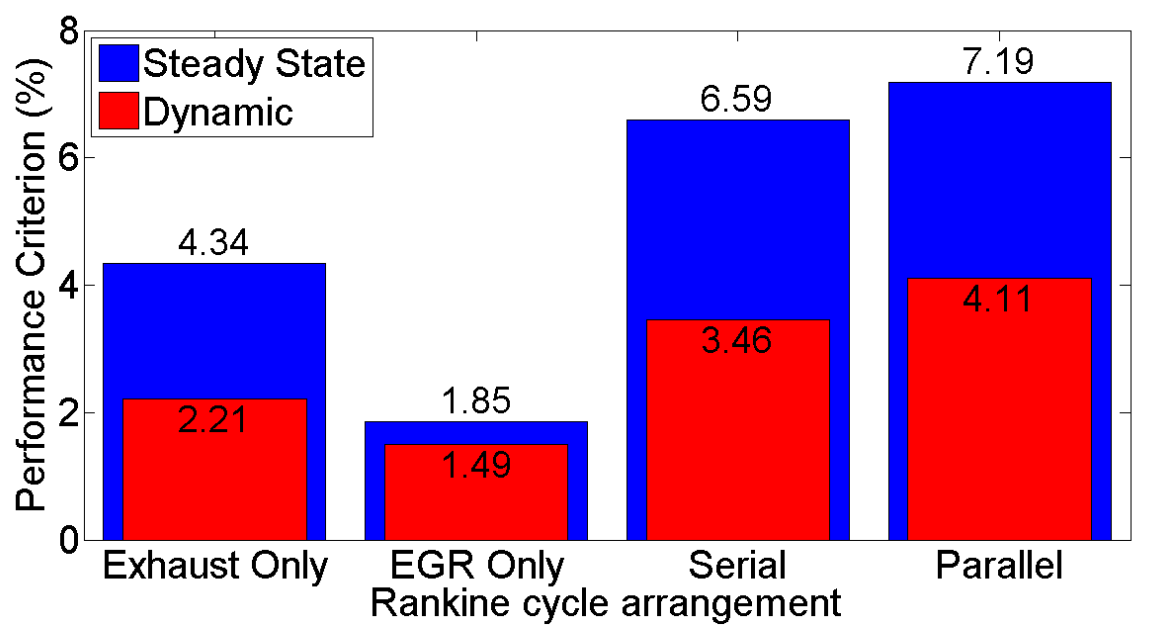

Figure 17: $P C$ for optimal sizing of the components

\section{CONCLUSION}

Performance simulations of different WHRS for heavy duty trucks application was conducted to understand the potential of such a system in terms of fuel consumption decrease. Two different methodologies are used and discussed. Usually, only the first approach, which consists to split a driving cycle into several steady state engine operating points, is used to assess the performance without any regards of the transient behavior of the different components composing the WHRS [3]. The second one, where a total vehicle approach is simulated over a wide variety of dynamic driving cycles representing the usage of a long haul HD vehicle. In both methods architecture to architecture ranking is the same which tends to prove that the first approach could be used for qualitative but not quantitative study. Using the second approach results into lower fuel savings and needs to be balanced in regards of the model validation done based onto prototypes, which are not representing what could be a mass-produced system. However, the absolute numbers should not be interpreted as the maximal potential for WHRS in HD trucks, since transient control of the system and components are not optimal. Different systems layout have been analyzed to maximize the system performance over a broad variety of driving cycles. However the results presented in this paper need to be treated carefully and further completed with the cost and the packaging effort for each configurations. An optimized 
scenario is also presented where a specific attention has been paid to the components size and performance in order to perfectly match the application. However fuel savings are rather low compared to what can be found in the literature [45, 3] and need to be further validated by experimental results on a system mounted onto a vehicle. In addition to that, control issues are not approached in this paper but remain a big part of the system performance maximization. In this study, perfect sensors and actuators are used, which reduce the control effort. Moreover, actual mass-produced control units are not as powerful as current laptop central processing unit and reduce considerably the possibility in terms of advanced control algorithm development. Recent studies have brought significant advances in this field [46, 12, 47] but this still needs to be addressed when vehicle implementation is touched.

\section{REFERENCES}

[1] P. Patel, E. Doyle, Compounding the truck diesel engine with an organic rankine-cycle system, in: SAE Technical Paper, no. 760343, SAE International, 1976.

[2] S. Oomori, H. Ogino, Waste heat recovery of passenger car using a combination of rankine bottoming cycle and evaporative cooling system, in: SAE Technical Paper, no. 930880, SAE International, 1993.

[3] A. Boretti, Recovery of exhaust and coolant heat with R245fa organic rankine cycles in a hybrid passenger car with a naturally aspirated gasoline engine, Applied Thermal Engineering 36 (0) (2012) $73-77$.

[4] F. Willems, F. Kupper, R. Cloudt, Integrated powertrain control for optimal CO2-NOx tradeoff in an euro-vi diesel engine with waste heat recovery system, in: American Control Conference (ACC), 2012, 2012, pp. 1296-1301.

[5] R. Freymann, W. Strobl, A. Obieglo, The turbosteamer: A system introducing the principle of cogeneration in automotive applications, MTZ worldwide 69 (5) (2008) 20-27.

[6] T. Wang, Y. Zhang, Z. Peng, G. Shu, A review of researches on thermal exhaust heat recovery with rankine cycle, Renewable and Sustainable Energy Reviews 15 (6) (2011) 2862 - 2871. 
[7] C. Sprouse III, C. Depcik, Review of organic rankine cycles for internal combustion engine exhaust waste heat recovery, Applied Thermal Engineering 51 (1-2) (2013) $711-722$.

[8] N. Espinosa, Contribution to the study of waste heat recovery systems on commercial truck diesel engines, Ph.D. thesis, University of Liege, National Polytechnic Institute of Lorraine (10 2011).

[9] J. Dickson, M. Ellis, T. Rousseau, J. Smith, Validation and design of heavy vehicle cooling system with waste heat recovery condenser, SAE International Journal of Commercial Vehicles 7 (2014) 458-467.

[10] E. Wang, H. Zhang, Y. Zhao, B. Fan, Y. Wu, Q. Mu, Performance analysis of a novel system combining a dual loop organic rankine cycle (orc) with a gasoline engine, Energy 43 (1) (2012) 385 - 395, 2nd International Meeting on Cleaner Combustion (CM0901-Detailed Chemical Models for Cleaner Combustion).

[11] A. A. Boretti, Transient operation of internal combustion engines with rankine waste heat recovery systems, Applied Thermal Engineering 48 (2012) $18-23$.

[12] J. Peralez, P. Tona, O. Lepreux, A. Sciarretta, L. Voise, P. Dufour, M. Nadri, Improving the control performance of an organic rankine cycle system for waste heat recovery from a heavy-duty diesel engine using a model-based approach, in: 52nd Annual IEEE Conference on Decision and Control (CDC), 2013, pp. 6830-6836.

[13] S. Quoilin, M. V. D. Broek, S. Declaye, P. Dewallef, V. Lemort, Technoeconomic survey of organic rankine cycle (orc) systems, Renewable and Sustainable Energy Reviews 22 (2013) 168 - 186.

[14] S. Lecompte, H. Huisseune, M. van den Broek, S. D. Schampheleire, M. D. Paepe, Part load based thermo-economic optimization of the organic rankine cycle (orc) applied to a combined heat and power (chp) system, Applied Energy 111 (2013) $871-881$.

[15] T. A. Horst, W. Tegethoff, P. Eilts, J. Koehler, Prediction of dynamic rankine cycle waste heat recovery performance and fuel saving potential 
in passenger car applications considering interactions with vehicles' energy management, Energy Conversion and Management 78 (0) (2014) $438-451$.

[16] A. Legros, L. Guillaume, M. Diny, H. Zaïdi, V. Lemort, Comparison and Impact of Waste Heat Recovery Technologies on Passenger Car Fuel Consumption in a Normalized Driving Cycle, Energies 7 (8) (2014) $5273-5290$.

[17] E. Bredel, J. Nickl, S. Bartosch, Waste heat recovery in drive systems of today and tomorrow, MTZ worldwide eMagazine 72 (4) (2011) 52-56.

[18] R. Freymann, J. Ringler, M. Seifert, T. Horst, The second generation turbosteamer, MTZ worldwide 73 (2) (2012) 18-23.

[19] S. Flik, M. Edwards, E. Pantow, Emissions reduction in commercial vehicles via thermomanagement, in: Proceedings of the 30th wiener motorensymposium, Viena, Austria, 2009.

[20] P. J. Mago, L. M. Chamra, C. Somayaji, Performance analysis of different working fluids for use in organic rankine cycles, Proceedings of the Institution of Mechanical Engineers, Part A: Journal of Power and Energy 221 (3) (2007) 255-263.

[21] M. Z. Stijepovic, P. Linke, A. I. Papadopoulos, A. S. Grujic, On the role of working fluid properties in organic rankine cycle performance, Applied Thermal Engineering 36 (0) (2012) 406 - 413.

[22] A. I. Papadopoulos, M. Stijepovic, P. Linke, On the systematic design and selection of optimal working fluids for organic rankine cycles, Applied Thermal Engineering 30 (6-7) (2010) $760-769$.

[23] E. Cayer, N. Galanis, H. Nesreddine, Parametric study and optimization of a transcritical power cycle using a low temperature source, Applied Energy 87 (4) (2010) 1349 - 1357.

[24] S. Karellas, A. Schuster, A.-D. Leontaritis, Influence of supercritical ORC parameters on plate heat exchanger design, Applied Thermal Engineering 33-34 (0) (2012) $70-76$. 
[25] M. L. H. Eric. W. Lemmon, Refprop nist standard reference database 23 (version 9.0)), thermophysical properties division, national institute of standards and technology, boulder, co (May 2013). URL http://www.nist.gov/srd/nist23.cfm

[26] E. Feru, F. Kupper, C. Rojer, X. Seykens, F. Scappin, F. Willems, J. Smits, B. D. Jager, M. Steinbuch, Experimental validation of a dynamic waste heat recovery system model for control purposes, in: SAE Technical Paper, SAE International, 2013.

[27] T. A. Horst, H.-S. Rottengruber, M. Seifert, J. Ringler, Dynamic heat exchanger model for performance prediction and control system design of automotive waste heat recovery systems, Applied Energy 105 (0) (2013) $293-303$.

[28] M. Willatzen, N. Pettit, L. Ploug-Sørensen, A general dynamic simulation model for evaporators and condensers in refrigeration. part i: moving-boundary formulation of two-phase flows with heat exchange: Modèle général dynamique pour évaporateurs et condenseurs frigorifiques. partic i: Formulation des conditions aux limites variables de flux biphasiques avec échange de chaleur, International Journal of Refrigeration 21 (5) (1998) $398-403$.

[29] J. Judge, R. Radermacher, A heat exchanger model for mixtures and pure refrigerant cycle simulations, International Journal of Refrigeration 20 (4) (1997) $244-255$.

[30] S. Bendapudi, J. E. Braun, E. A. Groll, A comparison of movingboundary and finite-volume formulations for transients in centrifugal chillers, International Journal of Refrigeration 31 (8) (2008) 1437 - 1452.

[31] I. H. Bell, S. Quoilin, E. Georges, J. E. Braun, E. A. Groll, W. T. Horton, V. Lemort, A generalized moving-boundary algorithm to predict the heat transfer rate of counterflow heat exchangers for any phase configuration, Applied Thermal Engineering 79 (2015) $192-201$.

[32] I. Vaja, Definition of an object oriented library for the dynamic simulation of advanced energy systems: Methodologies, tools and applications to combined ice-orc power plants, Ph.D. thesis, University of Parma (05 2009). 
[33] J. R. Thome, Wolverine Tube Inc Engineering Data Book III, Heat Transfer Databook, Wolverine Tube Inc., 2010.

[34] J. Bao, L. Zhao, A review of working fluid and expander selections for organic rankine cycle, Renewable and Sustainable Energy Reviews 24 (2013) $325-342$.

[35] O. Badr, P. O'Callaghan, S. Probert, Performances of rankine-cycle engines as functions of their expanders' efficiencies, Applied Energy 18 (1) (1984) $15-27$.

[36] A. Costall, A. G. Hernandez, P. Newton, R. Martinez-Botas, Design methodology for radial turbo expanders in mobile organic rankine cycle applications, Applied Energy (2015) -.

[37] G. Latz, S. Andersson, K. Munch, Selecting an expansion machine for vehicle waste-heat recovery systems based on the rankine cycle, in: SAE Technical Paper, SAE International, 2013.

[38] H. Kunte, J. Seume, Partial admission impulse turbine for automotive orc application, in: SAE Technical Paper, SAE International, 2013.

[39] O. E. Baljé, A study on design criteria and matching of turbomachines: Part a - similarity relations and design criteria of turbines, Journal of Engineering Gas Turbines Power 84 (1) (1962) 83 - 102.

[40] D. Maraver, J. Royo, V. Lemort, S. Quoilin, Systematic optimization of subcritical and transcritical organic rankine cycles (orcs) constrained by technical parameters in multiple applications, Applied Energy 117 (0) (2014) $11-29$.

[41] S. Lecompte, H. Huisseune, M. van den Broek, B. Vanslambrouck, M. D. Paepe, Review of organic rankine cycle (orc) architectures for waste heat recovery, Renewable and Sustainable Energy Reviews 47 (0) (2015) 448 $-461$.

[42] S. Mavridou, G. Mavropoulos, D. Bouris, D. Hountalas, G. Bergeles, Comparative design study of a diesel exhaust gas heat exchanger for truck applications with conventional and state of the art heat transfer enhancements, Applied Thermal Engineering 30 (8-9) (2010) 935 - 947. 
[43] R. Stobart, S. Hounsham, R. Weerasinghe, The controllability of vapour based thermal recovery systems in vehicles, in: SAE Technical Paper, SAE International, 2007.

[44] J. Fischer, Comparison of trilateral cycles and organic rankine cycles, Energy 36 (10) (2011) $6208-6219$.

[45] S. Edwards, J. Eitel, E. Pantow, P. Geskes, R. Lutz, J. Tepas, Waste heat recovery: The next challenge for commercial vehicle thermomanagement, SAE International Journal of Commercial Vehicles 5 (2012) 395-406.

[46] D. Luong, T.-C. Tsao, Linear quadratic integral control of an organic rankine cycle for waste heat recovery in heavy-duty diesel powertrain, in: American Control Conference (ACC), 2014, 2014, pp. 3147-3152.

[47] S. Quoilin, R. Aumann, A. Grill, A. Schuster, V. Lemort, H. Spliethoff, Dynamic modeling and optimal control strategy of waste heat recovery organic rankine cycles, Applied Energy 88 (6) (2011) 2183 - 2190.

\section{APPENDIX}

\section{Nomenclature}

\section{Acronyms}

$C A C$ Charge air cooler

$C F C$ Chlorofluorocarbon

$C F D$ Computational fluid dynamics

EATS Exhaust after treatment system

EGR Exhaust gas recirculation

GADSL Global automotive declarable substance list

$G W P$ Global warming potential

$H C F C$ Hydrochlorofluorocarbon

$H D$ Heavy duty

$H E X$ Heat exchanger

NFPA National fire protection agency 


\begin{tabular}{|c|c|c|}
\hline 780 & NOP & Net output power \\
\hline 1 & $N T U$ & Number of transfer unit \\
\hline 782 & $O D P$ & Ozone depletion potential \\
\hline 783 & $O R C$ & Organic Rankine cycle \\
\hline 784 & $P C$ & Performance criterion \\
\hline 785 & \multicolumn{2}{|c|}{$W H R S$ Waste heat recovery system } \\
\hline 786 & \multicolumn{2}{|c|}{ Greek letters } \\
\hline 787 & $\alpha$ & Heat transfer coefficient $\left(W / m^{2} / K\right)$ \\
\hline 788 & $\epsilon$ & Heat exchanger efficiency $(-)$ \\
\hline 789 & $\eta$ & Efficiency $(-)$ \\
\hline 790 & $\gamma$ & Specific heat ratio $(-)$ \\
\hline 791 & $\lambda$ & Heat conductivity $(W / m / K)$ \\
\hline 792 & $\omega$ & Angular velocity $(\mathrm{rad} / \mathrm{s})$ \\
\hline 793 & $\phi$ & Compresibiliy factor $(-)$ \\
\hline 794 & $\rho$ & Density $\left(k g / m^{3}\right)$ \\
\hline 795 & $\varphi$ & Critical pressure ratio $(-)$ \\
\hline 796 & \multicolumn{2}{|c|}{ Latin letters } \\
\hline 797 & $\dot{m}$ & Mass flow $(k g / s)$ \\
\hline 798 & $\dot{Q}$ & Heat flow rate $(W)$ \\
\hline 799 & $\dot{q}$ & Linear heat flow rate $(W / m)$ \\
\hline 800 & $\dot{W}$ & Power $(W)$ \\
\hline 801 & $A$ & Area $\left(m^{2}\right)$ \\
\hline 802 & $C_{c}$ & Cubic capacity $\left(m^{3}\right)$ \\
\hline 803 & $C_{d}$ & Discharge coefficient $(-)$ \\
\hline 804 & $c_{p}$ & Specific heat $(J / k g / K)$ \\
\hline 805 & $G$ & Gear ratio $(-)$ \\
\hline 806 & $h$ & Enthalpy $(J / k g)$ \\
\hline 807 & $K_{e q}$ & Equivalent throat diameter $\left(m^{2}\right)$ \\
\hline 808 & $N$ & Rotational speed (rpm) \\
\hline 809 & $N u$ & Nusselt number $(-)$ \\
\hline 810 & $P$ & Pressure $(P a)$ \\
\hline 811 & $P e$ & Perimeter $(m)$ \\
\hline
\end{tabular}




\begin{tabular}{|c|c|c|}
\hline 812 & $P P$ & Pinch point $(K)$ \\
\hline 813 & $r$ & Ideal gas constant $(\mathrm{J} / \mathrm{kg} / \mathrm{K})$ \\
\hline 814 & $S$ & Section $\left(m^{2}\right)$ \\
\hline 815 & $s$ & Entropy $(\mathrm{J} / \mathrm{kg} / \mathrm{K})$ \\
\hline 816 & $S r$ & Vehicle to ram air speed ratio $(-)$ \\
\hline 817 & $T$ & Temperature $(K)$ \\
\hline 818 & $t$ & Time $(s)$ \\
\hline 819 & $V$ & Volume $\left(m^{3}\right)$ \\
\hline 820 & $w$ & Driving cycle weight $(-)$ \\
\hline 821 & $x$ & Quality (-) \\
\hline 822 & $z$ & Spatial direction $(m)$ \\
\hline \multicolumn{3}{|c|}{823 Subscripts } \\
\hline 824 & air & Air \\
\hline 825 & $a m b$ & Ambient \\
\hline 826 & $\operatorname{conv}$ & Convection \\
\hline 827 & cross & Cross section \\
\hline 828 & $e f f$ & Effective \\
\hline 829 & egr & EGR gas \\
\hline 830 & $\operatorname{Egr} B$ & EGR boiler \\
\hline 831 & eng & Engine \\
\hline 832 & $e x h$ & Exhaust gas \\
\hline 833 & $\operatorname{Exh} B$ & Exhaust boiler \\
\hline 834 & $\exp$ & Expander \\
\hline 835 & ext & External wall \\
\hline 836 & $f$ & Working fluid \\
\hline 837 & fan & Cooling fan \\
\hline 838 & $g$ & Gas \\
\hline 839 & in & Inlet port \\
\hline 840 & int & Internal wall \\
\hline 841 & $\max$ & Maximum \\
\hline 842 & $\min$ & Minimum \\
\hline 843 & out & Outlet port \\
\hline
\end{tabular}




$\begin{array}{lll}844 & \text { pump } & \text { Pump } \\ { }_{845} & \text { tank } & \text { Tank } \\ { }_{846} & v & \text { Valve } \\ { }_{847} & \text { vol } & \text { Volumetric } \\ { }_{848} & \text { wall } & \text { Heat exchanger wall }\end{array}$

